\title{
El encuadre del islam y los musulmanes: la cobertura periodística en España ${ }^{1}$
}

\author{
Framing of Muslims and Islam: newspaper coverage in Spain
}

\section{Rafael DURÁN}

Universidad de Málaga ${ }^{2}$

rduran@uma.es

http://orcid.org/0000-0003-3293-314X

Recibido 5/12/2018. Revisado y aceptado para publicación 12/4/2019.

Para citar este artículo: Rafael DURÁN (2019), "El encuadre del islam y los musulmanes: la cobertura periodística en España" en Revista de Estudios Internacionales Mediterráneos, pp.160-185.

Para acceder a este artículo: https://doi.org/10.15366/reim2019.26.010

\begin{abstract}
Spain ranks low among European democracies regarding negative attitudes toward Muslims and Islam. Islamophobia does not appear to be a contentious issue in the Spanish political arena as to the definition of 'us,' even though Moroccans have become the largest migrant community, and even though Spain is currently one of the three major Member States of first entry into the Union from Middle East and North Africa. By conducting a media frame analysis, the aim of this paper is to know whether and to what extent the Spanish large-circulation quality newspapers portray Muslims and Islam as strange, monolithic and problematic. Variations according to ideology and the nature of the events reported are taken into account. This is an empirical and longitudinal study covering an entire year. Conclusions are expected to further contribute to comparative investigations.
\end{abstract}

Keywords: Islam/Muslims/Frame Theory/Islamophobia

\section{Resumen}

La actitud negativa de los españoles hacia el islam y los musulmanes está entre las más bajas de las democracias europeas. La islamofobia no aparece como un tema de confrontación en el debate público acerca de qué es ser español, no obstante haberse convertido la nacionalidad marroquí en la mayoritaria de cuantas conforman la población inmigrante y contarse España entre los tres Estados miembros con mayor entrada de extranjeros procedentes del Magreb y de Oriente Próximo. El objeto de este artículo es, mediante la teoría del encuadre, analizar la medida en que

\footnotetext{
${ }^{1}$ Investigación desarrollada en el marco del proyecto DER2017-84178-P (Plan Nacional de I+D+I, Ministerio de Economía, Industria y Competitividad)

${ }^{2}$ Profesor Titular de la Universidad de Málaga.
} 
la prensa ha proyectado una imagen de lo islámico como algo extraño, monolítico y problemático. Se abordan asimismo posibles variaciones en función de la ideología de los periódicos y de la naturaleza de los acontecimientos de que se informa. El estudio, empírico y longitudinal, analiza el año 2017 en su integridad. Se espera que las conclusiones contribuyan a estudios comparados.

Palabras clave: España / Narrativa / Ideología / Discurso / Magreb

\section{Introducción}

Según la Unión de Comunidades Islámicas de España (UCIDE, 2018), en 2017 la "población musulmana" residente en el país casi alcanzó los 1,95 millones de integrantes. Extranjeros y españoles incluidos, y entre éstos los nacionalizados, son unas 400.000 personas más que apenas seis años antes (idem, 2012). De manera complementaria, los marroquíes, mayoritariamente musulmanes, se han convertido en la primera comunidad nacional de inmigrantes ${ }^{3}$. Como en otros países occidentales, también en España se ha constatado a lo largo de los últimos años un incremento del rechazo y aun de los incidentes de odio hacia los musulmanes ${ }^{4}$. Europa, concluye De Bellaigue, "se ha vuelto más antimusulmana conforme se ha hecho más musulmana" (2018); es más: a su juicio, "mientras la población musulmana siga creciendo tan rápidamente, el islam seguirá causando aprensión entre muchos europeos" (idem; vide Kaufmann y Goodwin, 2018).

Rechazando la premisa de la incompatibilidad entre las personas de cultura y/o credo musulmán y los valores occidentales, pero también la premisa de que Occidente tiene una opinión y una actitud hacia el islam y los musulmanes (Brown, 2006; Greenberg y Miazhevich, 2012; Bowe y Makki, 2016), este estudio tiene por objeto analizar la imagen que de lo islámico se está trasladando a la ciudadanía por parte de los medios de comunicación en España. ¿En qué medida la prensa española está contribuyendo a la inclusión/exclusión del musulmán como parte de una realidad multicultural de la que el islam también forma parte? Hay estudios empíricos al respecto de otros países, pero escasean sobre el caso planteado ${ }^{5}$. Dada la relevancia política de los medios de comunicación como agentes conformadores de la opinión pública y siendo agentes también socializadores, resulta oportuno interesarse por el imaginario colectivo de lo islámico que contribuyen a moldear. Después de todo, forma parte de nuestra política exterior y de seguridad, como está presente en nuestras plazas y mercados, y hace acto de presencia en el momento definidor, las elecciones, de nuestra forma institucionalizada de convivencia.

No es extraño encontrarse con opiniones críticas también por parte de musulmanes respecto de la imagen distorsionada que los medios ofrecen del islam, sea en entrevistas académicas en profundidad (Desrues y Pérez-Yruela, 2008; Butler-Sloss y Kessler, 2015), en grupos de discusión

\footnotetext{
${ }^{3}$ Según los datos provisionales del Instituto Nacional de Estadística, el Padrón de Habitantes de 2018 registra 769.050 marroquíes, que superan de esta forma a las comunidades años atrás más numerosas: los rumanos (673.017) y los británicos (240.934).

${ }^{4}$ Pueden consultarse los informes de islamofobia en Europa de la Foundation for Political, Economic and Social Research, con análisis específicos por países, en http://www.islamophobiaeurope.com. Para el caso español, pueden verse asimismo los informes anuales de la Plataforma Ciudadana contra la Islamofobia, disponibles en http://plataformaciudadanacontralaislamofobia.org (vide Cea et al., 2014; Durán, 2014).

${ }^{5}$ Martín et al. (1997), Piquer (2015) y Zurbano et al. (2017) estarían entre las excepciones. Cabe destacar la labor que está realizando el Observatorio de la Islamofobia en los Medios (disponible en http://www.observatorioislamofobia.org). De manera más o menos tangencial, a lo islámico se hacen referencias en estudios sobre la inmigración (v.gr., Abella, 2006). Para el análisis de la representación de los musulmanes en internet en España, vide Alcántara-Pla y Ruiz-Sánchez (2017).
}

REIM № 26 (junio 2019) ISSN: $1887-4460$ 
(Mijares y Lems, 2018) o en encuestas (Ameli y Merali, 2015: 5.21 a 5.23). Como destacan Ahmed y Matthes (2016), los estudios han constatado que sienten a los medios sesgados en su contra; llaman la atención los autores, por otra parte, sobre el hecho de que esa valoración ha propiciado el alejamiento de las minorías musulmanas de las sociedades de las que forman parte, creencias y prácticas religiosas al margen (Kunst et al., 2012). Es un comentario crítico que suele hacerse en términos genéricos, sin apoyo en la evidencia empírica y no solo por parte de los propios musulmanes; como cuando Alba afirma que "los medios nos han presentado siempre el islam como una fuerza homogénea y absorbente (...) sistemáticamente descrita como amenazadora y negativa" (2015: 69), o Cebolla y González Ferrer, que la "tendencia discriminatoria hacia los musulmanes en general en toda la Unión Europea [es] reflejo de los arraigados estereotipos de los que se suelen hacer eco los medios de comunicación" (2008: 251-252; vide Revenga y El Mouden, 2010: 7; Martín, 2012: 42). Nos proponemos en este estudio abordar la cuestión en términos cuantitativos, mediante análisis de contenido, para así calibrar con datos ese sesgo por tantos asumido.

Toda vez que los medios de comunicación contribuyen a la conformación de la opinión pública con su discurso, ¿es este islamófobo en España? En palabras de Corm, ¿“alimentan miedos, tensiones y hostilidades" (2004: 34) hacia los musulmanes?, ¿son "policías de (...) almas" (idem: 16) que imponen una visión dicotómica, que enfrenta en clave binaria un nosotros, los occidentales, y un ellos, el otro oriental (Said, 1990), el otro extraño (Bauman, 2016), el otro musulmán (vide Said, 2005)? Al intentar responder nos preguntaremos asimismo la medida en que los medios mantienen un único discurso común, hegemónico, y si eventuales diferencias entre ellos podrían explicarse en términos ideológicos (en razón de la línea editorial) y/o territoriales (en razón de la presencia de musulmanes en el espacio periodístico de referencia).

\section{La islamofobia como objeto de estudio}

Lo islámico ha adquirido una presencia mediática en lo que va de siglo XXI desconocida en el XX. Hablamos de la prensa occidental. El punto de inflexión han sido los atentados del 11 de septiembre de 2001, el $11-S^{6}$. No solo se ha producido un cambio cuantitativo, sino también cualitativo: aunque el cambio de paradigma ya se constata con anterioridad (Brown, 2006), es a partir de entonces cuando se hace hegemónico el enfoque mediático del islam ligado al fanatismo y la amenaza para Occidente, al terrorismo en última instancia (Ruigrok y Van Atteveldt, 2007), frente a la imagen exótica y sensual del mismo que imperaba con anteriodidad. Como han indicado Berbers et al. (2016), se trata de una tendencia en la cobertura periodística del islam y los musulmanes que va de la mano de la creciente islamofobia. Para Corm, se ha impuesto así una "fractura imaginaria", una "visión dicotómica" (2004: 18), en clave binaria y negativa, de Occidente, nosotros, y Oriente, ellos (Saeed, 2007; Ibrahim, 2010). A Said (1990; vide idem, 2005) se debe esa concepción del orientalismo, esto es, la crítica de la orientalización del otro musulmán a partir de la cual se construye y define, desde su rechazo y el temor al mismo, el yo occidental (Ahmed y Matthes, 2016; Khader, 2016; Creutz-Kämppi, 2008). Reconociendo la aportación de Said, autores como Corral entienden que, más apropiado que hablar de orientalismo, es utilizar el término islamofobia (2014: 8).

La islamofobia es una forma de racismo. Implica el rechazo de los musulmanes, no por rasgos fenotípicos, a los que respondía el racismo tradicional, sino en razón, principalmente, de su identidad religioso-cultural. El racismo antimusulmán es un discurso, una actitud y/o un

\footnotetext{
${ }^{6}$ Vide Nacos y Torres-Reyna (2007) para el caso estadounidense, Roggeband y Vliegenthart (2007) para el holandés o Baker et al. (2013a) para el británico.
} 
comportamiento que no debe confundirse con la crítica de cuestiones islámicas o del islam en general (Imhoff y Recker, 2012). Implica un rechazo de los musulmanes en tanto que tales y en su totalidad. En el extremo, siendo una forma de odio, implicaría un deseo de que a los musulmanes les vaya mal o, de que, siendo distintos del nosotros que los rechaza (por temor o por odio), no disfruten de nuestros bienes. Suele entenderse que la islamofobia se da con el recelo y el rechazo, sin necesidad de que esté presente también el deseo de mal. Bleich destaca el carácter "indiscriminado" de tal hostilidad (2011, en Bowe et al., 2015: 49); la 'Runnymede Trust Commission on British Muslims and Islamophobia', por su parte, llama la atención sobre lo "infundado" de la misma (Richardson, 1997: 4). De manera complementaria, como asimismo han indicado Bayrakli y Hafez, siendo "fluidas" las imágenes islamófobas y variando de un contexto a otro, "la islamofobia dice más del islamófobo que de los musulmanes/islam" (2016: 7).

El primer informe Runnymede (Richardson, 1997) se ha convertido en una referencia de los estudios sobre islamofobia ${ }^{7}$. En él se concretan ocho indicadores, ocho items que permiten discriminar entre visiones "abiertas" y "cerradas" del islam: si el islam es visto 1) como monolítico y estático o diverso y dinámico; 2) como distinto y separado o similar e interdependiente; 3) como inferior o diferente, pero igual, y 4) como un enemigo agresivo o un aliado cooperativo, así como 5) si los musulmanes son vistos como manipuladores o sinceros; 6) si las críticas islámicas de Occidente son rechazadas o debatidas; 7) si las discriminaciones de los musulmanes son defendidas o rechazadas, y 8) si el discurso antimusulmán es visto como normal o problemático.

Sin referirse al informe Runnymede, Alba (2015) ha venido a sintetizar los ocho indicadores de islamofobia en tres "mecanismos" o "procedimientos" con los que se construye, en gran medida mediáticamente, "un otro manipulable y eventualmente exterminable": la reducción del otro musulmán a una unidad (un actor homogéneo) negativa (amenazante) e "inasimilable" ("incurable"). A propósito de los refugiados, resultan analíticamente interesantes las tres "estrategias narrativas" de delimitación o "fronterización simbólica" (symbolic bordering) del otro que han distinguido Chouliaraki y Zaborowski (2017): el silenciamiento (procedimiento por el que se les niega la voz en el discurso periodístico), la colectivización (la reducción del individuo a miembro indiferenciado de la masa) y la ausencia de contextualización del fenómeno al abordarlo. Centrándose en la dimensión populista (Hadiz y Chryssogelos, 2017) del fenómeno, Hafez (2017 y 2010) ha introducido el concepto populismo islamófobo para referirse al que ve al pueblo amenazado, no por una élite perversa, sino por el islam. También este autor entiende que el islam es concebido, así, como un cuerpo homogéneo, al tiempo que estático y monolítico, por una parte, y por otra, reaccionario, hostil, excluyente, etc. (vide Martín, 2012: esp.42).

El grueso de los estudios empíricos sobre la cobertura mediática del islam y los musulmanes atienden a la imagen positiva o negativa que se ofrece de los mismos. En su revisión de la literatura, Ahmed y Matthes han constatado que son comunes a los países estudiados, sin apreciarse significativas diferencias ni siquiera entre europeos y asiáticos (2016: 19), tanto las representaciones negativas como la cuestión nacional de la integración de los musulmanes, un asunto asimismo atendido como problema. En síntesis de Kaya, "[d]esde hace al menos más de una década (...) a la mayoría de los inmigrantes de origen musulmán y a sus descendientes en las

\footnotetext{
${ }^{7}$ Así lo acreditan Anderson (2015) y Bowe y Makki (2016). En conmemoración de su vigésimo aniversario, Runnymede ha publicado un segundo informe, en el que actualiza y amplía la evidencia islamófoba británica (Elahi y Khan, 2017). Sobre la dimensión estructural de la islamofobia, su vínculo con el racismo y sus mecanismos de construcción, vide item v.gr. Hajjat y Mohammed (2016) y Massoumi et al. (2017).
} 
sociedades europeas (...) [s]e los suele relacionar con la ilegalidad, la delincuencia, la violencia, las drogas, el radicalismo, el fundamentalismo, los conflictos $y$, en muchos otros aspectos, se los representa de forma negativa" (2017: 64). En efecto, la problematización del islam aparece también en análisis sobre la cobertura de la inmigración. En su estudio longitudinal, Roggeband y Vliegenthart (2007) constataron que lo islámico aparecía de una manera destacada en la prensa holandesa como amenaza a las normas y valores nacionales.

Así era por cuestiones como la separación entre iglesia y Estado, la aceptación de la homosexualidad, la igualdad de género y la libertad de expresión. De esta manera, a la amenaza a la seguridad física y económica, tan presente en el discurso mediático a propósito de la inmigración, se suma la "amenaza para la seguridad cultural" en el caso de los musulmanes (Kaya, 2017: 60; vide Berbers et al., 2016) ${ }^{8}$. Se trata de un discurso que contrapone el islam a los valores occidentales -cuando no también a los de la cristiandad (Creutz-Kämppi, 2008)- y que ha nutrido las críticas a las políticas multiculturalistas en pro de las asimilacionistas (Keskinen, 2014). No asistimos, por tanto, al conocimiento de las diferencias del igual diferente, sino a su otrificación. El otro musulmán, convertido de esta manera en homo islamicus, resulta ser un "extraño amenazante" (Creutz-Kämppi, 2008: 298). De acuerdo con la aproximación ensayística de Khader, "[I]as representaciones mediáticas resucitan la imagen de un Oriente eterno, guerrero, violento, machista, fanático y despótico" (2016).

\section{El enfoque mediático del islam y los musulmanes}

El periodismo "consiste en hacer cosas con palabras, no solo en usar palabras" (Chouliaraki, 2013: 268). En la medida en que actúa sobre las percepciones de realidad de las personas, es "una práctica performativa" (Chouliaraki y Zaborowski, 2017: 616; cursiva añadida). Los medios de comunicación se sirven de tres mecanismos fundamentales al informar y conformar la opinión pública: seleccionan los asuntos que consideran noticias (contribuyen a establecer la agenda de temas de interés público), los jerarquizan y adoptan un punto de vista, un enfoque, esto es, ayudan a entender y confieren un significado a las cuestiones que abordan. El análisis cuantitativo de esos aspectos de la labor periodística (análisis de contenido) y de su incidencia en las relaciones de poder se lleva a cabo por medio de las correspondientes y respectivas teorías del establecimiento de la agenda (agenda-setting theory), del priming y del enfoque (framing theory). Entman se ha referido a las tres teorías como "instrumentos de poder" (2007: 163) ${ }^{9}$. La teoría más extendida usando metodología cualitativa es el Análisis Crítico del Discurso (ACD) ${ }^{10}$. Quizás la mayor producción académica en torno a lo islámico sea la sustentada en la teoría del enfoque. Es un campo de estudio no explorado respecto del caso español. El presente estudio pretende cubrir ese hueco.

\footnotetext{
${ }^{8}$ Uno de los elementos que más parece haber colaborado al recelo y el rechazo del islam han sido prendas de vestir femeninas, el hiyab y el nicab singularmente. Para Luz Gómez, junto a la "islamofobia del yihadismo" y a la "de los refugiados", la "del hiyab" es uno de los tres "cortes icónicos (...) en la conformación del imaginario islam-amenaza" (2016). Sibai, por su parte, ha llamado la atención sobre el "discurso triplemente generizado" de esta islamofobia resultante en la "construcción de la mujer musulmana con hiyab" (2017: 114 [cursivas de la autora]; vide Navarro, 2012).

${ }^{9}$ Desde la teoría del agenda-setting se ha demostrado que el énfasis mediático en una cuestión determinada, una vez seleccionada para informar de ella, incide en la importancia asignada a la misma por la ciudadanía (McCombs y Shaw, 1972; Bulkow et al., 2013).

${ }^{10}$ Para el autor de referencia del ACD, Van Dijk, "los medios informativos no describen ni registran los sucesos noticiables del mundo de forma pasiva, sino que los (re)construyen activamente" (1997: 79). Lo hacen como parte de las élites con cuyo discurso se (re)construyen las "representaciones sociales compartidas" de la realidad (idem, 1993: 257).
} 
Quienes se aproximan al estudio de la cobertura mediática atendiendo a los enfoques han analizado cuantitativamente la medida en que los medios, además de fijar la agenda pública (de temas), inducen en el público una forma de pensar sobre tales temas, una forma de entenderlos (De Vreese et al., 2011; Scheufele e Iyengar, 2011; Scheufele y Tewksbury, 2007). De ahí que haya autores que hablen de encuadres cognitivos o interpretativos y de marcos de interpretación o comprensión de un fenómeno (Albizu, 2016). Dado que una misma noticia puede ser cubierta de distintas formas, y puesto que la forma en que es cubierta por los medios condiciona el procesamiento cognitivo y actitudinal, los enfoques son lo que lleva a interpretar de distinta forma un mismo asunto en función del que adopte el medio. De acuerdo con la definición clásica de Entman (1993), enmarcar conlleva, a partir de la selección de la cuestión sobre la que se va a informar, promocionar una definición determinada de dicha cuestión, una interpretación causal, una evaluación moral y/o una propuesta de actuación o solución. La definición del objeto implica la identificación del sujeto, un aspecto que a su vez ha hecho recomendable atender a las fuentes y voces con que se elaboran los textos periodísticos, sobre todo por ver la medida en que están presentes en los relatos los propios sujetos o se les silencia, si son o no "sujetos con voz" (Chouliaraki y Zaborowski, 2017) $^{11}$. Es por todo este mecanismo múltiple como los medios, no determinan (Bowe et al., 2015), pero sí inducen opiniones, actitudes, creencias, intenciones de conducta y comportamientos, además de provocar emociones (Slone, 2000).

Parece cierta la afirmación de que opinión pública es lo que queda después de la acción de los medios de comunicación (Luhmann, 2000). El efecto de los medios en quienes se exponen a ellos está medido y acreditado, también en relación con lo islámico. En su revisión de la literatura, Ahmed y Matthes (2016) constatan que el incremento de la islamofobia en EE.UU. entre 2004 y 2008, mayor que en Europa, puede explicarse en relación con el dispar tratamiento mediático del islam y los musulmanes, más prejuicioso en el caso americano. En el ámbito de la teoría del enfoque y mediante diseño experimental, Saleem et al. (2015) han comprobado que los ciudadanos son tanto más propensos a apoyar políticas que perjudican a los musulmanes cuanto más se exponen a coberturas que los representan como terroristas ${ }^{12}$, y matizan (vide infra) que, afectando a medio plazo con independencia de la ideología, a corto plazo incide mayormente en los conservadores. Atendiendo a las cadenas de televisión por las que suelen informarse los ciudadanos, McElwee y McDaniel (2015) han constatado que, teniendo los republicanos en EE.UU. una mayor percepción de los musulmanes como personas violentas que los demócratas, se reduce la diferencia entre ellos y aumenta la percepción negativa por parte de ambos grupos cuando ven con regularidad la cadena Fox News. En relación con las políticas públicas, Uitermark y Giele (2010) han observado en un estudio de caso que las autoridades nacionales actúan contra el radicalismo en unas mezquitas, no porque sea el problema ni las necesidades de un barrio, sino por haberse visto impelidas a ello por la cobertura mediática.

Roggeband y Vliegenthart (2007) han detectado cinco enfoques en su estudio comparativo de los discursos mediático y político en Holanda acerca de la inmigración y la integración de los inmigrantes. Siendo de carácter positivo solo uno de ellos (enfoque "multiculturalista") y haciendo de la inmigración un problema los otros cuatro, el que más presencia ha adquirido desde el 11-S

\footnotetext{
${ }^{11}$ Felicetti y Gattinara (2018) han comprobado en su análisis de la cobertura de The Guardian de los atentados contra Charlie Hebdo (2015) que las mujeres y los grupos religiosos, los musulmanes en particular, tuvieron una visibilidad limitada, como los actores que cuestionaron la narrativa securitaria dominante.

${ }^{12}$ Givens y Luedtke (2005) han constatado que el mero incremento de las noticias sobre inmigración contribuye a que las políticas correspondientes sean más restrictivas.
} 
ha sido el enfoque del "islam como amenaza", enfoque que, centrado en los valores y la cultura, ya predominaba en el discurso mediático con anterioridad ${ }^{13}$. También de Holanda, D'Haenens y Bink (2007) han comprobado que los enfoques mediáticos problematizan las consecuencias económicas y cuestiones de moralidad al abordar lo islámico. En su estudio sobre el caso australiano, Anderson ha comparado las coberturas con enfoque "abierto" y "cerrado"14, y ha observado una variación en el tiempo en favor del primero; a su juicio, como respuesta por las críticas recibidas por los medios en vista de sus coberturas "injustas, sesgadas e inflamatorias" de mediados de la primera década del siglo en curso (2015: 265). También con carácter binario, Bowe et al. (2015) han estudiado la cobertura estadounidense tras el 11-S atendiendo al tono ${ }^{15}$ : enfoque "positivo" vs. "negativo", esto es, la medida en que los musulmanes aparecen como miembros de la sociedad, a la cual contribuyen, o como una amenaza para la misma, y han concluido que, predominando el enfoque negativo sobre el positivo, la cobertura neutra es la que más presencia tiene. Asimismo en relación con los enfoques de la prensa en EE.UU., del New York Times en su caso, Greenberg y Miazhevich han observado un cambio significativo: de un tono de "simpatía" (enfoque multiculturalista) a uno de "abierta hostilidad y otrificación" (enfoque asimilacionista) (2012: 91; cursivas en el original).

Que predomine un encuadre, negativo, no implica que sea el único. En su estudio de caso, Roggeband y Vliegenthart (2007) han constatado que la variedad de enfoques es una realidad, si bien es mayor en el discurso parlamentario que en el mediático. En consonancia con Bowe et al. (2015), Bowe y Makki han concluido de su estudio de las mezquitas como cuestión de debate público que "sería una sobresimplificación decir que las representaciones de los musulmanes son uniformemente negativas" (2016: 551). La literatura de referencia pone de manifiesto que la diversidad y frecuencia de enfoques varía en función de la línea editorial (de izquierda o de derecha), del tipo de periódico (tabloide o 'de calidad') y del territorio, al menos en el caso de los países con nacionalismos infraestatales. Mediante el ACD, Baker et al. (2013a y 2013b) han observado una cobertura más equilibrada en los periódicos de izquierda y una mayor tendencia a asociar islam y terrorismo entre los tabloides. Scalvini, por su parte, concluye que "la prensa conservadora expresa preocupación ante el crecimiento de la diversidad cultural y religiosa", mientras que la progresista se centra más en "promocionar la cohesión social y en perseguir conjuntamente la inclusión y la integración" (2016: 624). Berbers et al. (2016) han constatado que los diarios "de calidad" y los de izquierda adoptan encuadres menos problematizadores de lo islámico que los tabloides y los de derecha; siendo su estudio sobre los musulmanes residentes en Bélgica que se fueron a luchar a Siria contra Bachar al-Assad en 2013, han observado asimismo que los diarios flamencos prestaron más atención al asunto y lo cubrieron, frente a la opción temática o contextualizadora, más mediante el enfoque episódico o anecdótico que los valones ${ }^{16}$.

Que predomine un encuadre, negativo, no implica que sea el único. En su estudio de caso, Roggeband y Vliegenthart (2007) han constatado que la variedad de enfoques es una realidad, si bien es mayor en el discurso parlamentario que en el mediático. En consonancia con Bowe et al.

\footnotetext{
${ }^{13}$ También Chouliaraki y Zaborowski (2017) han resaltado cómo lo cultural se relaciona negativamente con lo islámico, en su caso a propósito de la acogida de refugiados en Europa, siendo de carácter geopolítico (terrorismo) y económico (crisis económica) los otros aspectos negativos más importantes con que se identifica a estas personas.

${ }^{14}$ En línea con Anderson, aunque centrados en la cobertura de los refugiados en Europa y preocupados por la definición del nosotros, Chouliaraki y Zaborowski han diferenciado entre el enfoque "cosmopolita" ("abierto, hospitalario e inclusivo") y el "comunitarista", que definen como “cerrado, fóbico e introvertido" (2017: 615; vide Gilson y Photiadou, 2017; Slaughter, 2017).

${ }^{15}$ Bowe et al. (2015) utilizan indistintamente los términos "valence" y "tone".

${ }^{16}$ Sobre los enfoques episódico y temático, a partir de la aportación de lyengar (1994), vide Bowe y Makki (2016), Morin (2016) y Rodríguez-Pérez (2007).
} 
(2015), Bowe y Makki han concluido de su estudio de las mezquitas como cuestión de debate público que "sería una sobresimplificación decir que las representaciones de los musulmanes son uniformemente negativas" (2016: 551). La literatura de referencia pone de manifiesto que la diversidad y frecuencia de enfoques varía en función de la línea editorial (de izquierda o de derecha), del tipo de periódico (tabloide o 'de calidad') y del territorio, al menos en el caso de los países con nacionalismos infraestatales. Mediante el ACD, Baker et al. (2013a y 2013b) han observado una cobertura más equilibrada en los periódicos de izquierda y una mayor tendencia a asociar islam y terrorismo entre los tabloides. Scalvini, por su parte, concluye que "la prensa conservadora expresa preocupación ante el crecimiento de la diversidad cultural y religiosa", mientras que la progresista se centra más en "promocionar la cohesión social y en perseguir conjuntamente la inclusión y la integración" (2016: 624). Berbers et al. (2016) han constatado que los diarios "de calidad" y los de izquierda adoptan encuadres menos problematizadores de lo islámico que los tabloides y los de derecha; siendo su estudio sobre los musulmanes residentes en Bélgica que se fueron a luchar a Siria contra Bachar al-Assad en 2013, han observado asimismo que los diarios flamencos prestaron más atención al asunto y lo cubrieron, frente a la opción temática o contextualizadora, más mediante el enfoque episódico o anecdótico que los valones ${ }^{17}$.

\section{Objeto y diseño de la investigación}

Así como no todos los musulmanes son árabes, tampoco todos los árabes son musulmanes, y no hay una única forma de sentirse y ser musulmán. Es más: hay multiplicidad de ramas, corrientes, escuelas, ritos y cofradías entre quienes profesan la fe musulmana, de la misma forma que ni todos son islamistas ni todos los islamistas son fanáticos y violentos. Por otra parte, conociéndose el conservadurismo moral de muchos musulmanes, también los hay liberales ${ }^{18}$. Los musulmanes lo son por el contexto cultural en que nacen y crecen, pero no necesariamente por sus creencias religiosas ${ }^{19}$, como no todos los creyentes son practicantes ni con la misma intensidad. En todo caso, los musulmanes no son solo musulmanes; más allá de esa dimensión de su individualidad, los definen tantas otras como a cualquier igual humano.

El interrogante que de todo ello se deriva y que vertebra esta investigación es si el discurso mediático español reproduce esta complejidad o, por el contrario, construye un imaginario homogeneizador, excluyente y problematizador del islam y los musulmanes. El objeto de este estudio es, así, calibrar la medida en que el discurso mediático en España a propósito del islam y los musulmanes hace de ellos un otro extraño, racializado, del que recelar y al que rechazar, se les desee o no mal alguno explícitamente. En otras palabras, se trata de ver si en la prensa española también predomina un encuadre islamófobo o si, por el contrario, la pluralidad informativa se traduce en diversidad de enfoques y aun en predominio del enfoque integrador.

Según veíamos más arriba, la tríada homogeneización, exclusión y problematización es lo que caracteriza en última instancia a la islamofobia. Nuestro estudio es de naturaleza deductiva: no inferimos los enfoques que por otras vías pudieren detectarse en la cobertura mediática (método inductivo), sino que analizamos la medida en que están presentes los tres que interesan por los motivos analíticos aducidos. Tal y como se recoge en la figura 1 , se abordará la presencia de los

\footnotetext{
${ }^{17}$ Sobre los enfoques episódico y temático, a partir de la aportación de lyengar (1994), vide Bowe y Makki (2016), Morin (2016) y Rodríguez-Pérez (2007).

${ }^{18}$ Malik (2015) se refiere a ello apoyándose en una encuesta del Institut d'Études Opinion et Marketing en France et à I'International (IFOP) a musulmanes norteafricanos residentes en Francia.

${ }^{19}$ Sobre el ateísmo entre los culturalmente musulmanes, vide Rizvi (2016).
} 
enfoques inclusivo (el sujeto, parte del nosotros mediático de referencia, sea España, Europa u Occidente, pero también los demócratas o los seres humanos) vs. excluyente (el sujeto, un otro extraño). En segundo lugar, se discriminará si al hablar de lo islámico se asume como un todo homogéneo o como una realidad heterogénea, intrínsecamente variada. Finalmente, se valorará la medida en que el encuadre adoptado problematiza o no lo relativo al islam. Dado que la selección de recortes periodísticos que conforman la base documental se hace en función de la cobertura de lo islámico, la base de datos introduce un sesgo religioso; de ahí que no se vaya a estudiar la medida en que la prensa reduce a las personas de identidad cultural o fe musulmana a su dimensión religiosa ${ }^{20}$.

Los mensajes que transmiten los periodistas también pueden ser confusos, ambivalentes o imprecisos; en tales ocasiones, dada la imposibilidad o dificultad de determinar un enfoque dado, al codificar no se adscribirán los términos y/o los documentos a uno de los enfoques enfrentados, pues el tratamiento informativo no tendería a conformar la opinión en uno ni otro sentido, sino que se adscribirán a un tercero, el enfoque neutro (Anderson, 2015; Bowe et al., 2015; Durán, $2015)^{21}$.

Como primera hipótesis, cabe esperar que el enfoque predominante sea el islamófobo $\left(h_{1}\right)$, si bien es previsible que la cobertura conjunta de los medios sea plural en cuanto a los enfoques $\left(h_{2}\right)$ y que los medios de izquierda sean más plurales y tengan una mayor presencia del enfoque integrador que los de derecha $\left(h_{3}\right)$, con los medios de centro en una posición intermedia. Por otra parte, si bien el medio de centro del estudio no será español en sentido territorial, sino marcadamente catalán, pensamos que la ideología pesa más en el enfoque de lo islámico que la territorialidad $\left(h_{4}\right)$, en coherencia con los hallazgos del análisis de la crisis humanitaria de Lampedusa de 2011 (Durán, 2015) y no obstante el volumen de personas de identidad musulmana residentes en Cataluña (vide infra). No cabe esperar, en todo caso, que cada medio aborde uniformemente todos los temas que cubra $\left(h_{5}\right)$, por lo que también analizaremos las posibles variaciones internas y las coincidencias que puedan darse entre los diarios investigados.

Para responder al interrogante de la investigación y abordar las hipótesis planteadas, elaboramos a partir de la literatura revisada una matriz que nos permite identificar y cuantificar el o los encuadres con los que la prensa española aborda cuestiones relativas al islam y los musulmanes. Entendemos que los encuadres son la resultante de tres categorías analíticas: 1) la identificación del sujeto (cómo se encuadran el islam y los musulmanes); 2 ) las voces y fuentes del discurso (de quién se nutren los periódicos para construir su argumentario informativo), y 3) la definición o identificación del objeto noticioso (qué tema o cuestión se aborda). Para la primera categoría se codificarán las entradas "isl*m*" y "musulm*"22. La segunda categoría supone igualmente la codificación de todos los términos con que se concretan las personas, organizaciones 0 instituciones de cuyo parecer se da cuenta, sea en estilo directo (voces) o indirecto (fuentes). En

\footnotetext{
${ }^{20}$ Navarro (2012) ha apuntado la tendencia de los medios a cubrir cuestiones relativas a las mujeres musulmanas haciendo de su religión el factor explicativo de aquellas y dejando al margen explicaciones políticas, económicas o educativas. De ahí la importancia de señalar que quedan fuera de esta investigación los recortes periodísticos que no hayan islamizado el objeto informativo. Así, por ejemplo, se descarta la pieza de título "El largo y lento camino hacia la libertad de las mujeres" (EI País, 18-11-17, p.8) a propósito de reformas en Arabia Saudí, porque la religión no aparece en el título ni hay destacados o pies de foto que aludan al hecho religioso. En la segunda frase, por otra parte, no se alude al fundamentalismo religioso del régimen, sino al hecho de que es "uno de los reinos más conservadores del mundo".

${ }^{21}$ Eludimos la explicitación del enfoque neutro en la figura 1 en aras de la claridad expositiva.

${ }^{22}$ Los asteriscos responden a cualquier letra o conjunto de letras con las que conformar las múltiples palabras posibles; por ejemplo, desde "islam" hasta "islámico" o "islamista” (y sus plurales y posibles femeninos).
} 
fin, los temas de las noticias no se codificarán en palabras de los textos, sino para cada uno de estos. La matriz resultante permite consignar el enfoque adoptado (uno de cada par recogido en la columna central de la figura 1 para cada una de las categorías (columna de la izquierda). La sistematización del análisis (5.083 palabras o conjuntos de palabras han sido codificadas) se ha realizado mediante el programa informático Atlas.ti.

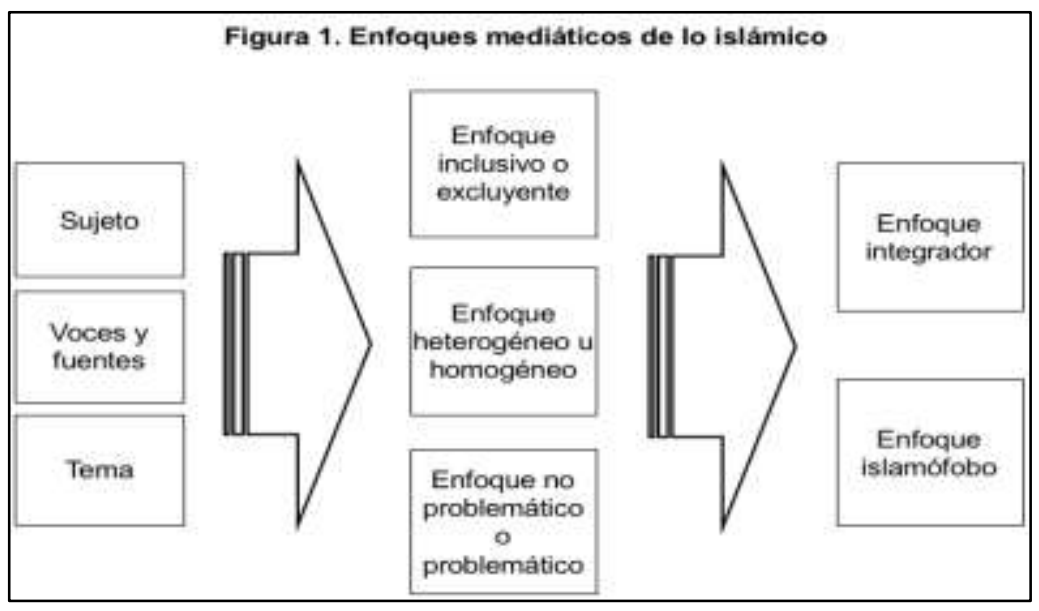

Muchos estudios se centran en la cobertura de hechos concretos, que por otra parte suelen haber sido noticia por las tensiones o conflictos a que han dado lugar: construcción de mezquitas (Bowe y Makki, 2016), caricaturas de Mahoma (Creutz-Kämppi, 2008), prohibición del uso del velo integral (Fernández-Suárez, 2016), etc. Interesa en este estudio, por el contrario, observar la normalidad que se construye mediáticamente a lo largo de un período de tiempo; en concreto, los doce meses de 2017. Esa normalidad es la que deviene el "habitus" de Bourdieu, el "sentido común" de cada tiempo histórico (2007: 117). Tras el 11-S y el 11- $\mathrm{M}^{23}, 2017$ no es un año significativamente conflictivo por cuestiones relacionadas con lo islámico, e incluso la crisis de los desplazamientos forzosos (siendo mayoritariamente musulmanes los refugiados llegados a Europa) redujo entonces su impacto mediático, más agudo en 2015 y, en menor medida, en 2016. Durante 2017 se siguieron perpetrando atentados yihadistas, pero no recibieron la misma atención mediática que los precedentes (De Bellaigue, 2018); tampoco en el caso de los de Cataluña, si bien hacen tanto más pertinente el estudio de ese año, por ver si el acontecimiento alteró la cobertura y en qué sentido.

\footnotetext{
${ }^{23}$ Tras Nueva York, Madrid fue la mayor ciudad occidental en sufrir atentados yihadistas, el 11 de marzo de 2004 . Las seguiría Londres al año siguiente. A partir de entonces se sucederían los ataques en los mismos y otros lugares occidentales (Neumann, 2016; Hoffman y Reinares, 2014). En cuanto al uso del adjetivo yihadistas, se lo aplican a sí mismos los terroristas que obran desde su fundamentalista y violenta interpretación del islam. Aunque hay quienes desde el conocimiento de los textos de referencia de esta religión les niegan a los terroristas su propia condición de musulmanes, como contraponen a la yihad como guerra santa la yihad como lucha interior espiritual, en este estudio optamos por calificar el terrorismo en cuestión como yihadista. Tal adjetivo permite reconocer la naturaleza religiosa de la justificación y aspiraciones de quienes lo practican sin hacerlo sinónimo de islam o islámico ni de islamismo o islamista; se intenta, así, evitar una asociación errónea de ideas entre islam y terrorismo, sino incluso entre islam y violencia. En fin, dejar el sustantito terrorismo sin adjetivar o calificarlo de internacional no permite diferenciarlo de otros terrorismos, caso del islamófobo, una variante del supremacista blanco. Para profundizar en cuestiones terminológicas y sus complejas ramificaciones, vide Gómez (2019).
} 


\section{Los datos}

El análisis se centra en tres de los seis periódicos españoles de información general con más lectores diarios a lo largo de 2017: de mayor a menor número de lectores, El País (en adelante, $E P)$, La Vanguardia $(L V)$ y $A b c(A B C)$. Son asimismo los tres cuyo sitio en internet ha tenido un mayor número de visitantes únicos según las oleadas de la Encuesta General de Medios (EGM) correspondientes $^{24}$. Justifica la elección, en fin, su orientación ideológica y su sede editorial: si $A B C$ se sitúa en el espectro ideológico de la derecha, EP lo hace en el centro-izquierda y LV queda en el centro (Castromil, 2012; Humanes, 2014). ABC y EP se editan en Madrid y tienen una proyección nacional, mientras que LV se edita en Barcelona y es marcadamente catalán ${ }^{25}$. Interesa este aspecto, sobre todo, porque Cataluña es la región con mayor presencia de musulmanes (UCIDE, 2018), una variable que podría afectar al enfoque mediático y que justifica una de nuestras hipótesis.

La base de datos documental objeto de análisis se conforma por los recortes de prensa en que aparecen los términos "isl* $\mathrm{m}^{*}$ " $\mathrm{y}$ "musulm*". Aunque otros estudios limitan su selección a "islam" y "musulmán", femenino y plural incluidos (Bowe et al., 2015), añadimos a nuestras palabras de búsqueda "velo*", "pañuelo*", "hiyab*", "burka*", "mezquita*", "minarete*", "imam*" e "im*n*". Hemos utilizado para ello la hemeroteca digital MyNews. De las noticias sobre cuestiones internacionales solo se han incorporado al corpus documental aquellos recortes que destacan lo islámico utilizando los términos de búsqueda en los títulos, en los subtítulos, en las entradillas, en los destacados o en los pies de foto; son los recortes en los que, cualquiera que sea el hecho noticiado y el enfoque adoptado, se islamiza la cuestión, esto es, se aborda la cuestión poniéndola en relación con el islam (vide supra n.20). Toda vez que hay investigaciones centradas en la cobertura del terrorismo yihadista y a fin de evitar sesgos, se descartan de este estudio las piezas periodísticas sobre el mismo y sobre los conflictos bélicos en los países de mayoría musulmana. Analizados los despieces como recortes autónomos, la base documental se conforma finalmente por noticias propiamente dichas, reportajes, entrevistas, editoriales, columnas, artículos de opinión y cartas al director. Suman 432 unidades de análisis.

\section{Resultados}

Se han analizado 432 recortes de prensa, despieces incluidos. Es la atención periodística prestada por $A B C, E P$ y LV al islam y los musulmanes en 2017. EP cubrió tales contenidos o islamizó contenidos en menor medida que $A B C$ y LV (vide tabla 1), tanto por el número de piezas publicadas como por la extensión de la cobertura en número de palabras. Más marcadas son las diferencias entre los diarios, no obstante, por tipo de unidades de análisis: si bien los tres se decantan mayoritariamente por las noticias y los reportajes, $A B C$ concentra más de la mitad del total de portadas, de editoriales y de cartas; también supera ABC a EP y a LV en el espacio de opinión con más entradas: artículos y columnas.

\footnotetext{
${ }^{24}$ EGM de octubre de 2016 a mayo de 2017 y de abril de 2017 a marzo de 2018, disponibles en http://www.aimc.es.

${ }^{25}$ De acuerdo con la encuesta postelectoral del CIS de las generales de 2016 (Estudio 3.126), solo un cinco por ciento de los españoles que siguieron la actualidad política por la prensa lo hicieron principalmente por LV, pero es precisamente entre los votantes de partidos específicamente catalanes entre los que se cuentan los mayores porcentajes de lectores.
} 
Tabla 1. Atención mediática por palabras, días, documentos y tipo de documentos (2017)

\begin{tabular}{|c|c|c|c|c|c|c|c|c|}
\hline & & $\begin{array}{c}\text { Total } \\
\text { (3 diarios) }\end{array}$ & \multicolumn{2}{|c|}{$A b c$} & \multicolumn{2}{|c|}{ El País } & \multicolumn{2}{|c|}{ La Vanguardia } \\
\hline & & & Total & $(\%)^{*}$ & Total & $(\%)^{*}$ & Total & $(\%)^{*}$ \\
\hline \multirow{7}{*}{ 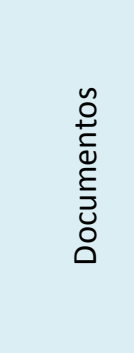 } & Total & 432 & 152 & $35,2 \%$ & 130 & $30,1 \%$ & 150 & $34,7 \%$ \\
\hline & Portada & 8 & 5 & $62,5 \%$ & 2 & $25,0 \%$ & 1 & $12,5 \%$ \\
\hline & Noticia o reportaje & 325 & 103 & $31,7 \%$ & 110 & $33,8 \%$ & 112 & $34,5 \%$ \\
\hline & Arts. de opinión & 70 & 32 & $45,7 \%$ & 15 & $21,4 \%$ & 23 & $32,9 \%$ \\
\hline & Cartas al director & 12 & 8 & $66,7 \%$ & 1 & $8,3 \%$ & 3 & $25,0 \%$ \\
\hline & Editoriales & 7 & 4 & $57,1 \%$ & 1 & $14,3 \%$ & 2 & $28,6 \%$ \\
\hline & Entrevistas & 10 & 0 & $0,0 \%$ & 1 & $10,0 \%$ & 9 & $90,0 \%$ \\
\hline Palabras & & 246.800 & 77.581 & $31,4 \%$ & 73.527 & $29,8 \%$ & 95.691 & $38,8 \%$ \\
\hline Días** & & 200 & 85 & & 86 & & 105 & \\
\hline
\end{tabular}

* Porcentajes de fila, en relación con el total correspondiente de los tres diarios.

** Días con recortes periodísticos. La suma de los días de cobertura de cada diario suma más de 200 porque hay días en que coinciden dos o los tres periódicos con piezas sobre el islam o los musulmanes. Fuente: Elaboración propia.

La cobertura mediática se distribuye a lo largo de todo el año, con registros acumulados en algo más de la mitad de los días (vide tabla 1). LV es el diario que más días dedica alguna atención a nuestro objeto de estudio (menos de un tercio de los 365), siendo la cobertura de ABC y EP inferior a la cuarta parte del año. En el $67 \%$ (ABC y LV) y en el 70\% (EP) de esos días solo se registra una entrada periodística. $A B C$ solo recoge más de dos entradas en 17 ediciones, 10 en el caso de EP y 8 en el de LV. Apenas cuatro noticias españolas suscitan más de dos piezas en un mismo día, sean del mismo diario o de más de uno: la sentencia de un juzgado avalando el derecho de una mujer a vestir el hiyab en su jornada laboral y la prohibición de que lo use una reclusa por yihadismo, la campaña de la diócesis de Córdoba en defensa de la propiedad y catolicidad de la Mezquita-Catedral, y los atentados terroristas de agosto en Barcelona y Cambrils. Las otras noticias que más atención han recibido en un mismo día son relativas a la vestimenta de las mujeres musulmanas (burka y hiyab); a la sentencia del Tribunal de Estrasburgo sobre la obligación de las menores a acudir a sus clases escolares de natación con independencia de sus creencias religiosas; a los atentados islamófobos de Canadá y el Reino Unido; a la orden ejecutiva del presidente de los EEUU prohibiendo la entrada de amplios colectivos musulmanes en el país, así como a su viaje oficial a Arabia Saudí y a su relación con la organización islamófoba Britain First; a las elecciones generales holandesas; al viaje pontificio a Egipto, y a la huida de rohinyás de Birmania a Bangladés. De todas ellas, solo el viaje pontificio y los atentados del Reino Unido (islamófobo) y de España (yihadista) fueron la noticia predominante durante más de un día, siete en el caso de estos últimos (vide infra).

\section{Enfoques y categorías analíticas}

Los datos recién aportados apenas permiten deducir la opinión que los medios tienden a conformar entre los ciudadanos. A fin de analizar el enfoque adoptado al abordar cuestiones relativas a lo islámico (o al islamizar contenidos informativos), hemos introducido 100 códigos, correspondientes a: los tres diarios, los seis tipos de pieza periodística publicados, los nueve subenfoques y los de las categorías, que incluyen tanto los códigos que identifican a cada una de ellas como los de cada una de las voces y fuentes, por una parte, y de cada uno de los temas, por otra. Ello ha dado lugar a un total de 22.296 registros codificados. Procedemos a continuación a 
analizar el o los enfoques adoptados por los diarios al referirse al islam o los musulmanes como sujetos de las informaciones y opiniones publicadas; seguidamente abordaremos, primero, las voces y fuentes en que se apoyan las piezas periodísticas para sostener su discurso y, en la tercera sección, los temas que tratan, al tiempo que analizaremos igualmente los enfoques adoptados en cada una de estas categorías.

\section{El sujeto islámico mediatizado}

En la tabla 2 se recogen los enfoques adoptados por los periódicos del estudio cada vez que se refieren al islam o los musulmanes como sujeto. Habiéndose codificado más de 5.000 registros, se constata que la cobertura lo encuadra mayoritariamente como un sujeto ajeno al nosotros (enfoque excluyente). Cabe destacar asimismo el alto porcentaje de registros de enfoque neutro, superior al inclusivo; son las ocasiones en que, al referirse al sujeto islámico, no se explicita si se les considera parte de o ajenos al nosotros de referencia.

Tabla 2. Encuadre mediático del islam y los musulmanes como sujeto: registros codificados de cada enfoque (2017)

\begin{tabular}{|l|c|c|c|c|c|c|c|c|}
\hline & \multicolumn{2}{|c|}{ Los tres diarios } & \multicolumn{2}{|c|}{ Abc } & \multicolumn{2}{c|}{ El País } & \multicolumn{2}{c|}{ La Vanguardia } \\
\hline & Registros & $\% *$ & Registros & $\% *$ & Registros & $\% *$ & Registros & $\% *$ \\
\hline Enfoque inclusivo & 369 & $24,5 \%$ & 104 & $17,6 \%$ & 167 & $40,5 \%$ & 98 & $19,5 \%$ \\
\hline Enfoque neutro & 403 & $26,8 \%$ & 125 & $21,2 \%$ & 114 & $27,7 \%$ & 164 & $32,6 \%$ \\
\hline Enfoque excluyente & 734 & $48,7 \%$ & 362 & $61,3 \%$ & 131 & $31,8 \%$ & 241 & $47,9 \%$ \\
\hline $\begin{array}{l}\text { Enfoque } \\
\text { heterogéneo }\end{array}$ & 543 & $27,9 \%$ & 157 & $22,4 \%$ & 170 & $31,4 \%$ & 216 & $30,8 \%$ \\
\hline Enfoque neutro & 114 & $5,9 \%$ & 35 & $5,0 \%$ & 32 & $5,9 \%$ & 47 & $6,7 \%$ \\
\hline $\begin{array}{l}\text { Enfoque } \\
\text { homogéneo }\end{array}$ & 1.287 & $66,2 \%$ & 510 & $72,6 \%$ & 339 & $62,7 \%$ & 438 & $62,5 \%$ \\
\hline $\begin{array}{l}\text { Enfoque no } \\
\text { problemático }\end{array}$ & 770 & $39,6 \%$ & 197 & $28,1 \%$ & 312 & $57,7 \%$ & 261 & $37,3 \%$ \\
\hline Enfoque neutro & 400 & $20,6 \%$ & 148 & $21,1 \%$ & 98 & $18,1 \%$ & 154 & $22,0 \%$ \\
\hline $\begin{array}{l}\text { Enfoque } \\
\text { problemático }\end{array}$ & 772 & $39,8 \%$ & 356 & $50,8 \%$ & 131 & $24,2 \%$ & 285 \\
\hline \begin{tabular}{l} 
Total \\
\hline
\end{tabular} & 5.392 & & 1.994 & & 1.494 & & 1.904 & $40,7 \%$ \\
\hline
\end{tabular}

* Porcentajes de columna y por grupos de enfoques Fuente: elaboración propia

La cobertura periodística también es mayoritariamente homogeneizadora del ellos musulmán, un segundo elemento de la islamofobia que podría estar impregnando o fomentando el tratamiento mediático de lo islámico. En este caso, además, se constata que el enfoque neutro está poco presente. Por el contrario, y en contra de la problematización de lo musulmán que caracteriza la cobertura mediática de otros países occidentales, en el caso español 1) hay un equilibrio en el tratamiento entre los enfoques problemático y no-problemático del sujeto islámico y 2) el problemático es, de los tres enfoques islamófobos, el menos presente.

De manera complementaria, las variantes binarias de cada enfoque (inclusivo vs. excluyente, etc.) no solo tienen una significativa presencia en el cómputo global de la cobertura mediática, sino también en las unidades que la conforman: de los 380 documentos en los cuales se hace referencia explícita al sujeto islámico (vide tabla 2 bis), los distintos enfoques están presentes en al menos el 32\% de ellos. Si bien predominan las piezas periodísticas con el sujeto encuadrado de manera excluyente, son más (con una diferencia de al menos 9,5 puntos porcentuales) las que contienen registros con el sujeto encuadrado de forma heterogénea (no todos los musulmanes son iguales) y no problemática. Hay, pues, diversidad de enfoques, y no es el islamófobo el que 
predomina. En relación con la mayor frecuencia de registros homogeneizadores antes apuntada, el análisis de su distribución por documentos indica, en fin, que esos registros están concentrados en poco más de un tercio de los documentos.

Tabla 2 bis. Encuadre mediático del islam y los musulmanes como sujeto: documentos con registros codificados de cada enfoque (2017)

\begin{tabular}{|l|c|c|c|c|c|c|c|c|}
\hline & \multicolumn{2}{|c|}{ Los tres diarios } & \multicolumn{2}{c|}{ Abc } & \multicolumn{2}{c|}{ El País } & \multicolumn{2}{c|}{ La Vanguardia } \\
\hline & Documentos & $\% *$ & Docs. & $\% *$ & Docs. & $\% *$ & Docs. & $\% *$ \\
\hline Enfoque inclusivo & 123 & $32,4 \%$ & 38 & $28,6 \%$ & 40 & $35,4 \%$ & 45 & $33,6 \%$ \\
\hline Enfoque neutro & 180 & $47,4 \%$ & 72 & $54,1 \%$ & 46 & $40,7 \%$ & 62 & $46,3 \%$ \\
\hline $\begin{array}{l}\text { Enfoque } \\
\text { excluyente }\end{array}$ & 174 & $45,8 \%$ & 57 & $42,9 \%$ & 49 & $43,4 \%$ & 68 & $50,7 \%$ \\
\hline $\begin{array}{l}\text { Enfoque } \\
\text { heterogéneo }\end{array}$ & 179 & $47,1 \%$ & 53 & $39,8 \%$ & 59 & $52,2 \%$ & 67 & $50,0 \%$ \\
\hline Enfoque neutro & 329 & $86,6 \%$ & 116 & $87,2 \%$ & 92 & $81,4 \%$ & 121 & $90,3 \%$ \\
\hline $\begin{array}{l}\text { Enfoque } \\
\text { homogéneo }\end{array}$ & 143 & $37,6 \%$ & 42 & $31,6 \%$ & 48 & $42,5 \%$ & 53 & $39,6 \%$ \\
\hline $\begin{array}{l}\text { Enfoque no } \\
\text { problemático }\end{array}$ & 248 & $65,3 \%$ & 69 & $51,9 \%$ & 87 & $77,0 \%$ & 92 & $68,7 \%$ \\
\hline Enfoque neutro & 249 & $65,5 \%$ & 97 & $72,9 \%$ & 58 & $51,3 \%$ & 94 & $70,1 \%$ \\
\hline $\begin{array}{l}\text { Enfoque } \\
\text { problemático }\end{array}$ & 204 & $53,7 \%$ & 68 & $51,1 \%$ & 54 & $47,8 \%$ & 82 & $61,2 \%$ \\
\hline Total & 380 & & 133 & & 113 & & 134 & \\
\hline
\end{tabular}

* Porcentaje respecto del total de documentos con registros de sujeto Fuente: elaboración propia

El desglose de los datos de registros por diario (tabla 2) pone de manifiesto diferencias relevantes: tanto en $A B C$ como en LV es siempre mayor la presencia del enfoque islamófobo que la del integrador, si bien las diferencias en puntos porcentuales entre cada variante binaria son siempre superiores en $A B C$ (de derecha y editado en Madrid) que en LV (de centro/Barcelona). Por el contrario, EP (izquierda/Madrid) informa del sujeto islámico con predominio de los enfoques inclusivo y no-problemático. $Y$, si también en EP tiene mayor presencia el enfoque homogéneo que el heterogéneo, la diferencia en puntos porcentuales es la menor de los tres diarios.

El enfoque homogéneo, por otra parte, no siempre tiene una connotación negativa. Sin negar lo errado y aun perjudicial de aludir a los musulmanes como comunidad diferenciada hacia el exterior e indiferenciada hacia el interior, no es menos cierto que también se alude a ellos en tales términos sin connotación islamófoba alguna. Así fue, por ejemplo, cuando la prensa recogió las palabras del primer ministro canadiense a propósito de un atentado de extrema derecha en Quebec; diciendo que se había perpetrado "contra los musulmanes", añadió: "estamos con vosotros", y precisó: "enriquecéis el país que compartimos en un número incontable de formas" ${ }^{26}$. Homogeneizándolos, expresaba su concepción de un nosotros que los incluía (enfoque incluyente), $y$, lejos de verlos como un problema, eran objeto de una violencia que rechazaba (noproblemático).

La diversidad de enfoques con independencia del diario queda también recogida en la tabla 2 bis: estando todos presentes en los tres diarios, el enfoque que en menos documentos está aparece en al menos el $29 \%$ del total respectivo; es el caso de los recortes de $A B C$ y del enfoque inclusivo. Si bien los tres diarios publican más piezas conteniendo registros de enfoque excluyente que

\footnotetext{
${ }^{26}$ Abc, 31-1-17, p.26.
} 
incluyente, los otros dos enfoques islamófobos están menos presentes que los integradores. Habiendo pocas diferencias entre los diarios respecto del enfoque homogéneo/heterogéneo, sí que es significativa la presencia de registros no-problemáticos en el $77 \%$ de los documentos de EP, 29 puntos por encima del porcentaje de documentos del mismo periódico con registros problemáticos. A este respecto, $L V$ aparece menos integrador que $E P$, pero más que $A B C$, que equilibra el número de documentos en que se registran los enfoques problemático ( $n=68)$ y noproblemático $(n=69)$.

\section{Voces y fuentes con que se construye lo islámico}

En 350 de los 432 documentos se construye el relato periodístico apoyándose en voces y fuentes (en adelante, $V y F$ ). Se cuentan entre ellas institucionales, de la sociedad civil, de expertos, de celebridades y anónimas o desconocidas (vox populi). Además de filtrar los datos por diario, hemos diferenciado las $\mathrm{VyF}$ en función de que fueran o no de musulmanes, y así comprobar si se comparte su voz con quienes se exponen a los medios.

Se recogen opiniones y testimonios de no-musulmanes en el $71 \%$ de las 350 piezas (vide tabla 3.1). Aunque la cuantía de las que dan voz a los musulmanes es inferior, están en la mitad de los documentos. Sean o no musulmanas, predominan las $\mathrm{VyF}$ institucionales, si bien los demás actores están también presentes, especialmente de la sociedad civil. Las institucionales no-musulmanas, en todo caso, son las únicas presentes en más de la mitad de los recortes. Por diarios, $A B C$ es el que en menos documentos recoge $\mathrm{VyF}$ musulmanas, al tiempo que es el medio que en menos recortes deja a los actores sin adscripción identitaria religiosa y el que en mayor medida incorpora las $\mathrm{VyF}$ de autoridades e instituciones no-musulmanas. No se observan diferencias significativas entre EP y LV, y, recogiendo ambas cabeceras a los musulmanes en al menos el $60 \%$ de sus documentos, las piezas en las que están presentes los no-musulmanes quedan al menos 13 puntos por debajo de la cobertura que les da ABC.

Tabla 3.1. Voces y fuentes en la cobertura de lo islámico (2017)

\begin{tabular}{|c|c|c|c|c|c|c|c|c|c|}
\hline & & \multicolumn{2}{|c|}{ Los tres diarios } & \multicolumn{2}{|c|}{$A b c$} & \multicolumn{2}{|c|}{ El País } & \multicolumn{2}{|c|}{ La Vanguardia } \\
\hline & & \multicolumn{2}{|c|}{ Docs. ${ }^{*}$} & \multicolumn{2}{|c|}{ Docs. } & \multicolumn{2}{|c|}{ Docs. } & \multicolumn{2}{|c|}{ Docs. } \\
\hline & & Total & $\% * *$ & Total & $\% * *$ & Total & $\% * *$ & Total & $\% * *$ \\
\hline \multirow{6}{*}{ 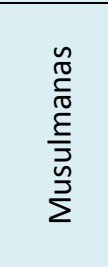 } & Insttcnales. & 121 & $34,6 \%$ & 43 & $37,4 \%$ & 33 & $30,0 \%$ & 45 & $36,0 \%$ \\
\hline & Soc. civil & 115 & $32,9 \%$ & 25 & $21,7 \%$ & 45 & $40,9 \%$ & 45 & $36,0 \%$ \\
\hline & Expertos & 38 & $10,9 \%$ & 10 & $8,7 \%$ & 12 & $10,9 \%$ & 16 & $12,8 \%$ \\
\hline & Celebridds. & 28 & $8,0 \%$ & 4 & $3,5 \%$ & 13 & $11,8 \%$ & 11 & $8,8 \%$ \\
\hline & Vox pop. & 82 & $23,4 \%$ & 20 & $17,4 \%$ & 32 & $29,1 \%$ & 30 & $24,0 \%$ \\
\hline & Total & 201 & $57,4 \%$ & 57 & $49,6 \%$ & 66 & $60,0 \%$ & 78 & $62,4 \%$ \\
\hline \multirow{6}{*}{ 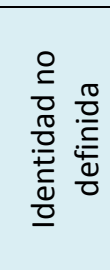 } & Insttcnales. & 45 & $12,9 \%$ & 5 & $4,3 \%$ & 12 & $10,9 \%$ & 28 & $22,4 \%$ \\
\hline & Soc. civil & 40 & $11,4 \%$ & 3 & $2,6 \%$ & 16 & $14,5 \%$ & 21 & $16,8 \%$ \\
\hline & Expertos & 22 & $6,3 \%$ & 2 & $1,7 \%$ & 5 & $4,5 \%$ & 15 & $12,0 \%$ \\
\hline & Celebridds. & 10 & $2,9 \%$ & 2 & $1,7 \%$ & 4 & $3,6 \%$ & 4 & $3,2 \%$ \\
\hline & Vox pop. & 37 & $10,6 \%$ & 6 & $5,2 \%$ & 17 & $15,5 \%$ & 14 & $11,2 \%$ \\
\hline & Total & 68 & $19,4 \%$ & 19 & $16,5 \%$ & 22 & $20,0 \%$ & 37 & $29,6 \%$ \\
\hline \multirow{6}{*}{ 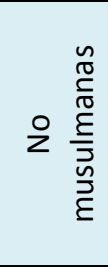 } & Insttcnales. & 185 & $52,9 \%$ & 72 & $62,6 \%$ & 56 & $50,9 \%$ & 57 & $45,6 \%$ \\
\hline & Soc. civil & 92 & $26,3 \%$ & 27 & $23,5 \%$ & 31 & $28,2 \%$ & 34 & $27,2 \%$ \\
\hline & Expertos & 57 & $16,3 \%$ & 20 & $17,4 \%$ & 14 & $12,7 \%$ & 23 & $18,4 \%$ \\
\hline & Celebridds. & 28 & $8,0 \%$ & 10 & $8,7 \%$ & 10 & $9,1 \%$ & 8 & $6,4 \%$ \\
\hline & Vox pop. & 80 & $22,9 \%$ & 22 & $19,1 \%$ & 30 & $27,3 \%$ & 28 & $22,4 \%$ \\
\hline & Total & 248 & $70,9 \%$ & 93 & $80,9 \%$ & 75 & $68,2 \%$ & 80 & $64,0 \%$ \\
\hline Total & & 350 & & 115 & & 110 & & 125 & \\
\hline
\end{tabular}

* Piezas periodísticas de la base de datos con registros codificados de voces y fuentes (VyF) 
** Porcentajes respecto del total de documentos con registros de $\mathrm{VyF}$, bien de los tres diarios juntos ( $\mathrm{N}=350)$ bien de cada uno de ellos ( $\mathrm{N}_{\mathrm{ABC}}=115, \mathrm{~N}_{\mathrm{EP}}=110$ y $\left.\mathrm{N}_{\mathrm{LV}}=125\right)$

Fuente: elaboración propia

Los enfoques inclusivo y excluyente tienen una presencia equilibrada, si bien sobresalen las VyF no-musulmanas sosteniendo un discurso excluyente (vide tabla 3.2). El predominio del enfoque islamófobo es mayor al atender a los encuadres homogéneo y heterogéneo, con una presencia de las VyF no-musulmanas más acentuada en este caso (61\% de los documentos). Por el contrario, no es el enfoque problemático el que predomina, sino que está equilibrado con el no-problemático, sean o no musulmanas las VyF. Por diarios, $A B C$ es menos inclusivo que $L V$, que a su vez lo es menos que EP, el más integrador tanto si atendemos a las $\mathrm{VyF}$ musulmanas como a las nomusulmanas. Aun así, los tres son más excluyentes que inclusivos, y es LV el que más documentos islamófobos publica con estas VyF. En sintonía con el enfoque inclusivo, también es EP el diario que, en términos relativos, en más piezas trata a los musulmanes como un colectivo heterogéneo, seguido por $L V$ y con $A B C$ incorporando esas $V y F$ en menos de un tercio de los documentos. Los tres presentan en más piezas las $V y F$ homogeneizadoras, más frecuentes en LV y en EP que en $A B C$.

En fin, de nuevo EP es el más integrador en relación con el enfoque no-problemático, seguido por LV, que no obstante es el más islamófobo en relación con el problemático, esto es, LV es el diario que más documentos publica, en términos relativos, con VyF sosteniendo un discurso problematizador de lo islámico. En sintonía con lo que indican los datos en relación con los pares dicotómicos inclusivo/excluyente $\mathrm{y}$ heterogeneizador/homogeneizador, tanto $A B C$ como LV presentan unos porcentajes también más elevados en el componente islamófobo que en el integrador del par problemático/no-problemático. Por el contrario, EP, con VyF problematizadoras en el $60 \%$ de los documentos, eleva el porcentaje significativamente al $84 \%$ al atender a las $\mathrm{VyF}$ no problematizadoras.

Que en un documento haya al menos un registro determinado no implica que haya muchos más. De ahí la relevancia de atender también a los propios registros en su conjunto. La tabla 3.3. revela, en sintonía con lo expuesto, que EP es el más inclusivo, así como el menos excluyente. También es el que en mayor medida proyecta una imagen heterogénea del islam y los musulmanes. En los tres medios predomina la representación homogénea, más acusada en $A B C$, que es también el medio más excluyente. Respecto del tercer binomio de enfoques, $A B C$ es, no sólo el medio que en mayor medida ofrece una imagen problemática, sino el único que construye su discurso apoyándose más veces en las VyF para enmarcarlo de manera problemática; cabe señalar, no obstante, que sus registros no problematizadores casi alcanzan el $40 \%$ y que los problematizadores apenas superan el $45 \%$ de los de este bloque. En el extremo, EP es el único que ofrece un porcentaje de registros no-problemáticos superior al $50 \%$ y problemático de apenas el $25 \%$. 
Tabla 3.2 Voces y fuentes en el enmarcado mediático de lo islámico (2017)

\begin{tabular}{|c|c|c|c|c|c|c|c|c|}
\hline & \multicolumn{5}{|c|}{ Los tres diarios } & \multirow{2}{*}{$\begin{array}{c}\text { ABC } \\
\text { Docs. }{ }^{*}\end{array}$} & \multirow{2}{*}{$\begin{array}{c}\text { EP } \\
\text { Docs.* }\end{array}$} & \multirow{2}{*}{$\begin{array}{c}\text { LV } \\
\text { Docs. }{ }^{*}\end{array}$} \\
\hline & & Docs.* & & Docs. & $\%^{* *}$ & & & \\
\hline \multirow{11}{*}{ Enfoque inclusivo } & \multirow{5}{*}{ Musulmanas } & \multirow{5}{*}{$\begin{array}{c}75 \\
(21,4 \%)\end{array}$} & Institucionales & 46 & $61,3 \%$ & \multirow{5}{*}{$\begin{array}{c}21 \\
(19,6 \%)\end{array}$} & \multirow{5}{*}{$\begin{array}{c}28 \\
(41,2 \%)\end{array}$} & \multirow{5}{*}{$\begin{array}{c}26 \\
(28,0 \%)\end{array}$} \\
\hline & & & Sociedad civil & 51 & $68,0 \%$ & & & \\
\hline & & & Expertos & 15 & $20,0 \%$ & & & \\
\hline & & & Celebridades & 9 & $12,0 \%$ & & & \\
\hline & & & Vox pop. & 38 & $50,7 \%$ & & & \\
\hline & Indefinidas & $\begin{array}{c}25 \\
(7,1 \%)\end{array}$ & & & & $\begin{array}{c}3 \\
(2,8 \%)\end{array}$ & $\begin{array}{c}9 \\
(13,2 \%)\end{array}$ & $\begin{array}{c}13 \\
(14,0 \%)\end{array}$ \\
\hline & \multirow{5}{*}{ No muslms. } & \multirow{5}{*}{$\begin{array}{c}106 \\
(30,3 \%)\end{array}$} & Institucionales & 81 & $76,4 \%$ & \multirow{5}{*}{$\begin{array}{c}34 \\
(31,8 \%)\end{array}$} & \multirow{5}{*}{$\begin{array}{c}33 \\
(48,5 \%)\end{array}$} & \multirow{5}{*}{$\begin{array}{c}39 \\
(41,9 \%)\end{array}$} \\
\hline & & & Sociedad civil & 47 & $44,3 \%$ & & & \\
\hline & & & Expertos & 20 & $18,9 \%$ & & & \\
\hline & & & Celebridades & 13 & $12,3 \%$ & & & \\
\hline & & & Vox pop. & 38 & $35,8 \%$ & & & \\
\hline \multirow{11}{*}{ Enfoque neutro } & \multirow{5}{*}{ Musulmanas } & & Institucionales & 56 & $60,9 \%$ & & & \\
\hline & & & Sociedad civil & 60 & $65,2 \%$ & & & \\
\hline & & 92 & Expertos & 20 & $21,7 \%$ & 27 & 26 & 39 \\
\hline & & & Celebridades & 11 & $12,0 \%$ & & & \\
\hline & & & Vox pop. & 48 & $52,2 \%$ & & & \\
\hline & Indefinidas & $\begin{array}{c}37 \\
(10,6 \%)\end{array}$ & & & & $\begin{array}{c}3 \\
(2,8 \%)\end{array}$ & $\begin{array}{c}11 \\
(16,2 \%)\end{array}$ & $\begin{array}{c}23 \\
(24,7 \%)\end{array}$ \\
\hline & & & Institucionales & 105 & $78,9 \%$ & & & \\
\hline & & & Sociedad civil & 56 & $42,1 \%$ & & & \\
\hline & No muslms. & 133 & Expertos & 33 & $24,8 \%$ & 43 & 42 & 48 \\
\hline & & & Celebridades & 12 & $9,0 \%$ & & & \\
\hline & & & Vox pop. & 51 & $38,3 \%$ & & & \\
\hline & & & Institucionales & 49 & $64,5 \%$ & & & \\
\hline & & & Sociedad civil & 41 & $53,9 \%$ & & & \\
\hline & Musulmanas & $\begin{array}{c}76 \\
(217 \%)\end{array}$ & Expertos & 20 & $26,3 \%$ & 44 & 34 & $\begin{array}{c}61 \\
656 \%)\end{array}$ \\
\hline & & & Celebridades & 11 & $14,5 \%$ & & & \\
\hline & & & Vox pop. & 31 & $40,8 \%$ & & & \\
\hline Enfoque excluyente & Indefinidas & $\begin{array}{c}23 \\
(6,6 \%)\end{array}$ & & & & $\begin{array}{c}8 \\
(7,5 \%)\end{array}$ & $\begin{array}{c}15 \\
(22,1 \%)\end{array}$ & $\begin{array}{c}26 \\
(28,0 \%)\end{array}$ \\
\hline & & & Institucionales & 93 & $69,9 \%$ & & & \\
\hline & & & Sociedad civil & 50 & $37,6 \%$ & & & \\
\hline & No muslms. & $\begin{array}{l}133 \\
128001\end{array}$ & Expertos & 38 & $28,6 \%$ & 54 & 32 & 53 \\
\hline & & & Celebridades & 16 & $12,0 \%$ & & & \\
\hline & & & Vox pop. & 42 & $31,6 \%$ & & & \\
\hline & & & Institucionales & 79 & $61,7 \%$ & & & \\
\hline & & & Sociedad civil & 78 & $60,9 \%$ & & & \\
\hline & Musulmanas & $\begin{array}{l}128 \\
(366 \%)\end{array}$ & Expertos & 28 & $21,9 \%$ & $\begin{array}{c}34 \\
(318 \%)\end{array}$ & $\begin{array}{c}44 \\
(647 \%)\end{array}$ & $\begin{array}{c}50 \\
(538 \%)\end{array}$ \\
\hline & & & Celebridades & 15 & $11,7 \%$ & & & \\
\hline & & & Vox pop. & 52 & $40,6 \%$ & & & \\
\hline Enfoque heterogéneo & Indefinidas & $\begin{array}{c}37 \\
(10,6 \%)\end{array}$ & & & & $\begin{array}{c}4 \\
(3,7 \%)\end{array}$ & $\begin{array}{c}13 \\
(19,1 \%)\end{array}$ & $\begin{array}{c}20 \\
(21,5 \%)\end{array}$ \\
\hline & & & Institucionales & 80 & $73,4 \%$ & & & \\
\hline & & & Sociedad civil & 51 & $46,8 \%$ & & & \\
\hline & No muslms. & 109 & Expertos & 31 & $28,4 \%$ & $1218 \% 1$ & 36 & 39 \\
\hline & & & Celebridades & 12 & $11,0 \%$ & & & \\
\hline & & & Vox pop. & 41 & $37,6 \%$ & & & \\
\hline & & & Institucionales & 77 & $68,1 \%$ & & & \\
\hline & & & Sociedad civil & 74 & $65,5 \%$ & & & \\
\hline & Musulmanas & 113 & Expertos & 21 & $18,6 \%$ & 31 & $\begin{array}{c}40 \\
458 \% 1\end{array}$ & 42 \\
\hline & & & Celebridades & 14 & $12,4 \%$ & $(29,0 \%)$ & & \\
\hline & & & Vox pop. & 51 & $45,1 \%$ & & & \\
\hline Enfoque neutro & Indefinidas & $\begin{array}{c}44 \\
(12,6 \%)\end{array}$ & & & & $\begin{array}{c}5 \\
(4,7 \%)\end{array}$ & $\begin{array}{c}13 \\
(19,1 \%)\end{array}$ & $\begin{array}{c}26 \\
(28,0 \%)\end{array}$ \\
\hline & & & Institucionales & 94 & $81,0 \%$ & & & \\
\hline & No muslms. & $\begin{array}{l}116 \\
(331 \%)\end{array}$ & Sociedad civil & 56 & $48,3 \%$ & $\begin{array}{c}39 \\
(36,4)\end{array}$ & $\begin{array}{l}36 \\
(529 \%)\end{array}$ & $\begin{array}{c}41 \\
(44,1 \%)\end{array}$ \\
\hline & & & Expertos & 28 & $24,1 \%$ & & & \\
\hline
\end{tabular}


Durán, El encuadre del Islam

\begin{tabular}{|c|c|c|c|c|c|c|c|c|}
\hline & & & Celebridades & 11 & $9,5 \%$ & & & \\
\hline & & & Vox pop. & 44 & $37,9 \%$ & & & \\
\hline & & & Institucionales & 98 & $62,0 \%$ & & & \\
\hline & & & Sociedad civil & 86 & $54,4 \%$ & & & \\
\hline & Musulmanas & 158 & Expertos & 36 & $22,8 \%$ & $\begin{array}{c}47 \\
(139 \%)\end{array}$ & 45 & 66 \\
\hline & & & Celebridades & 24 & $15,2 \%$ & & & \\
\hline & & & Vox pop. & 66 & $41,8 \%$ & & & \\
\hline Enfoque homogéneo & Indefinidas & $\begin{array}{c}53 \\
(15,1 \%)\end{array}$ & & & & $\begin{array}{c}6 \\
(5,6 \%)\end{array}$ & $\begin{array}{c}17 \\
(25,0 \%)\end{array}$ & $\begin{array}{c}30 \\
(32,3 \%)\end{array}$ \\
\hline & & & Institucionales & 160 & $74,8 \%$ & & & \\
\hline & & & Sociedad civil & 81 & $37,9 \%$ & & & \\
\hline & No muslms. & 214 & Expertos & 52 & $24,3 \%$ & 19 & 65 & 10 \\
\hline & & & Celebridades & 24 & $11,2 \%$ & & & \\
\hline & & & Vox pop. & 74 & $34,6 \%$ & & & \\
\hline & & & Institucionales & 86 & $62,3 \%$ & & & \\
\hline & & & Sociedad civil & 80 & $58,0 \%$ & & & \\
\hline & Musulmanas & $\begin{array}{c}138 \\
(39.4 \%)\end{array}$ & Expertos & 27 & $19,6 \%$ & $\begin{array}{c}35 \\
(32.7 \%)\end{array}$ & $\begin{array}{c}49 \\
(72,1 \%)\end{array}$ & $(58,1 \%)$ \\
\hline & & & Celebridades & 22 & $15,9 \%$ & & & \\
\hline & & & Vox pop. & 63 & $45,7 \%$ & & & \\
\hline Enfoque no problemático & Indefinidas & $\begin{array}{c}31 \\
(8,9 \%)\end{array}$ & & & & $\begin{array}{c}3 \\
(2,8 \%)\end{array}$ & $\begin{array}{c}18 \\
(26,5 \%)\end{array}$ & $\begin{array}{c}30 \\
(32,3 \%)\end{array}$ \\
\hline & & & Institucionales & 131 & $77,5 \%$ & & & \\
\hline & & & Sociedad civil & 70 & $41,4 \%$ & & & \\
\hline & No muslms. & 169 & Expertos & 34 & $20,1 \%$ & 53 & 102804 & 60 \\
\hline & & & Celebridades & 16 & $9,5 \%$ & & & \\
\hline & & & Vox pop. & 61 & $36,1 \%$ & & & \\
\hline & & & Institucionales & 91 & $65,5 \%$ & & & \\
\hline & & & Sociedad civil & 87 & $62,6 \%$ & & & \\
\hline & Musulmanas & $1397 \%$ & Expertos & 32 & $23,0 \%$ & $(36.4)$ & $(55,9 \%)$ & $(66,7 \%)$ \\
\hline & & & Celebridades & 17 & $12,2 \%$ & & & \\
\hline & & & Vox pop. & 56 & $40,3 \%$ & 5 & 14 & \\
\hline Enfoque neutro & Indefinidas & $(13,7 \%)$ & & & & $(4,7 \%)$ & $(20,6 \%)$ & $(31,2 \%)$ \\
\hline & & & Institucionales & 109 & $76,2 \%$ & & & \\
\hline & & & Sociedad civil & 65 & $45,5 \%$ & & & \\
\hline & No muslms. & $(409 \%)$ & Expertos & 42 & $29,4 \%$ & $(458 \%)$ & $(588 \%)$ & $(58,1 \%)$ \\
\hline & & & Celebridades & 18 & $12,6 \%$ & & & \\
\hline & & & Vox pop. & 50 & $35,0 \%$ & & & \\
\hline & & & Institucionales & 85 & $61,2 \%$ & & & \\
\hline & & & Sociedad civil & 83 & $59,7 \%$ & & & \\
\hline & Musulmanas & $1397 \%$ & Expertos & 29 & $20,9 \%$ & (41 1\%) & $(500 \%)$ & $(65.6 \%)$ \\
\hline & & & Celebridades & 18 & $12,9 \%$ & & & \\
\hline & & & Voxpop. & 57 & $41,0 \%$ & & & \\
\hline Enfoque problemático & Indefinidas & $\begin{array}{c}49 \\
(14,0 \%)\end{array}$ & & & & $\begin{array}{c}8 \\
(7,5 \%)\end{array}$ & $\begin{array}{c}15 \\
(22,1 \%)\end{array}$ & $\begin{array}{c}26 \\
(28,0 \%)\end{array}$ \\
\hline & & & Institucionales & 122 & $73,9 \%$ & & & \\
\hline & & & Sociedad civil & 68 & $41,2 \%$ & & & \\
\hline & No muslms. & $(471 \%)$ & Expertos & 46 & $27,9 \%$ & $(617 \%)$ & $(60.3 \%)$ & $(62.4 \%)$ \\
\hline & & & Celebridades & 19 & $11,5 \%$ & & & \\
\hline & & & Vox pop. & 56 & $33,9 \%$ & & & \\
\hline Total $* * *$ & & 350 & & & & 107 & 68 & 93 \\
\hline
\end{tabular}

* Entre paréntesis, porcentajes respecto del total de documentos con registros de voces y fuentes (VyF)

** Porcentajes respecto del total de documentos con registros de VyF musulmanas o no musulmanas correspondientes (tercera columna de la izquierda)

*** Total de documentos con registros de VyF Fuente: elaboración propia 


\section{Agenda temática de lo islámico y su enmarcado}

Codificados los documentos por los países o conjuntos de ellos, España apenas representa el 20\% de la cobertura mediática del islam y los musulmanes. El porcentaje es inferior al $70 \%$ si expandimos el horizonte territorial del nosotros a Occidente. Obsérvese (tabla 4) que en el $40 \%$ de los documentos no se hace referencia a noticias de otras realidades geográficas y culturales en general, sino, en concreto, a las noticias islamizadas sobre cuestiones internacionales ajenas al nosotros de referencia. Implica que, aun cubriendo los periódicos otros acontecimientos de países mayoritariamente musulmanes o que afectan a musulmanes, no se hace referencia a su identidad religiosa en tal abordaje; de ahí que la cobertura de esos acontecimientos (desislamizada o no islamizada) quede fuera de nuestra base de datos.

En relación con los enfoques, no se observan desequilibrios significativos entre los componentes de cada binomio. Cabe apuntar, en todo caso, a) la alta proporción de recortes excluyentes solo cuando se trata del mundo extraoccidental (mayoritariamente islámico); b) el predominio del encuadre homogeneizador en las noticias sobre España y sobre Occidente, no así en las que se refieren al resto del mundo, y c) que, estando igualadas la cobertura problemática y noproblemática al abordar los territorios no occidentales, se cubre lo español y lo occidental en mayor medida desde el enfoque no-problemático. En fin, así como destaca la escasa presencia de piezas excluyentes al abordar noticias españolas, es significativo que casi el $45 \%$ de los registros responda al enfoque neutro; al informar de personas en razón de su musulmanidad, no se las rechaza como extraños, pero tampoco se las incluye como propios.

La tabla 4 también recoge los temas de la cobertura. Los que más frecuencia de noticias tienen (entre el $15 \%$ y el $19 \%$ del total) son los temas relativos a la vestimenta con connotaciones religiosas, los que explícitamente se plantean la relación islam vis-à-vis 'nosotros' y los referidos tanto a la violencia que practican como a la violencia que padecen. Están asimismo por encima de la mediana los recortes sobre el islam como religión en general, sobre la mujer en el islam, sobre mezquitas e imanes, sobre Trump, sobre elecciones $y$, como piezas diferenciadas de las de violencia que sufren por ser musulmanes, las de islamofobia explícitamente referida; juntos suponen estos dos conjuntos de recortes el $25,5 \%$ de las unidades de análisis.

Considerados los temas uno a uno, hay un mayor predominio de los enfoques islamófobos. Una vez más, no obstante, destaca el encuadre no-problemático: en la mitad de los temas es superior al problemático; en la mayoría, por más de 20 puntos porcentuales de diferencia, destacando en el caso de las noticias sobre islamofobia y en las que, sin utilizarse el término, sí se pone de manifiesto alguna forma de violencia que sufren los musulmanes por serlo. Por contra, aparte de en las noticias con más cobertura recién referidas, se representa el islam como algo problemático sobre todo en las noticias sobre cuestiones culturales: familia (matrimonio, crimen de honor...), moral pública (blasfemia, homosexualidad...) y otras prácticas religioso-culturales (alimentación halal, circuncisión... $)^{27}$.

Analizados los temas uno a uno y teniendo en cuenta que codificamos el o los temas vertebradores de cada documento, solo ABC y LV llegan a dedicarle más del $20 \%$ de sus documentos a un tema dado, el de la violencia de los musulmanes. Aunando las piezas sobre la violencia que padecen y las que aluden explícitamente a la islamofobia, los tres han cubierto el

\footnotetext{
${ }^{27}$ Las enumeraciones entre paréntesis no implican abordaje problematizador de todas ellas. En todo caso, son pocas las noticias sobre otras prácticas religioso-culturales $(n=8)$.
} 
tema en más del $20 \%$ de sus noticias, si bien EP es el único que lo hace en más del $30 \%$ de su cobertura $(n=44)$.

Ninguno de los diarios sesga su mirada adoptando un único encuadre (vide tabla 4 bis), tampoco a propósito de si los musulmanes forman parte o no del nosotros, no obstante ser el enfoque excluyente el que predomina, como predomina el homogeneizador, ambos ligeramente más presentes en $A B C$ que en EP y LV. Las diferencias más significativas entre los tres diarios se aprecian en relación con si lo islámico supone o no un problema: por una parte, es la disyuntiva en la que en menor medida exponen los medios al público a una imagen imprecisa (enfoque neutro). Por otra, EP es el medio que menos temas enfoca problemáticamente y el que más encuadra de manera no-problemática, y ello tanto en el conjunto de temas como en aquellos a los que más atención presta; así, solo hay dos temas que aborde con enfoque mayoritariamente problematizador en más documentos que la mediana correspondiente.

Habiendo menos diferencias entre $A B C$ y $L V$ que con EP, se observa, pues, una cobertura algo más islamófoba en el primero que en el segundo. En sintonía con esta evidencia, $A B C$ traslada a sus lectores una imagen negativa del islam y los musulmanes con independencia de que las noticias sean relativas a España, se extiendan a Occidente o se refieran al resto de países, mientras que en EP predomina la visión desproblematizadora en los tres territorios, quedando LV en una posición intermedia (vide tabla 4bis).

Los atentados de Barcelona y Cambrils no aparecen como tema porque en este estudio se han excluido las noticias sobre terrorismo. Ello no impide que la prensa abordara cuestiones colaterales a la comisión de los crímenes de agosto y a la respuesta estatal consiguiente. De hecho, tales noticias han sido de las que más atención mediática han recibido; ninguna otra ha merecido tanta cobertura en un espacio concentrado de tiempo y por los tres diarios al unísono. Entre el 18 de agosto (día siguiente a los asesinatos de Barcelona ciudad) y el 5 de septiembre se publicaron 51 piezas, de las cuales 37 tenían los atentados como trasfondo. En sintonía con lo que cabría esperar por la reacción de la prensa occidental a los atentados yihadistas, ABC adoptó un enfoque mayormente excluyente, homogéneo y problemático en un mayor porcentaje de piezas durante esos días que en los siete meses y medio previos. Por el contrario, LV pasó de enfatizar el excluyente y el problemático a representar lo islámico mayormente en clave inclusiva y noproblemática, si bien en porcentajes algo menores que EP. En fin, aunque $A B C$ redujo tras el período de cobertura de los atentados el porcentaje de piezas con enfoque problemático (de 64\% a $45,4 \%$ ), siguió siendo el más presente en su cobertura, con un $42 \%$ de piezas de enfoque noproblemático; por el contrario, tanto EP (por encima del 50\%) como LV se siguieron decantando por la aproximación no-problemática al islam y los musulmanes.

\section{Conclusiones}

Las encuestas de opinión evidencian que la islamofobia es una actitud menos extendida en España que en países afines. El Pew Research Center (2018) ha visto, por ejemplo, que es el sexto país europeo, de un total de 34 (y el primero entre los mediterráneos), con más personas diciendo (74\%) que aceptarían musulmanes en su familia. El análisis del discurso mediático español abona la hipótesis de que bien podría ser aquel un factor coadyuvante de la actitud receptiva hacia quienes profesan el islam. 
Hemos analizado si la opinión y la actitud que la prensa tiende a conformar es islamófoba o integradora. Para ello hemos atendido a la medida en que se decanta, respectivamente, por los enfoques excluyente vs. inclusivo, homogeneizador vs heterogeneizador y problematizador o no de lo islámico. Lo hemos hecho teniendo en consideración tanto el total de registros codificados como los documentos en que aparecen tales registros en relación con las categorías sujeto y voces y fuentes. La tercera categoría ha sido la de los temas objeto de información u opinión, codificados como un único registro por documento.

La evidencia empírica demuestra que no hay una incitación a la acción violenta contra los musulmanes; no se trata de un discurso periodístico racista dirigido al, explícitamente contra el otro musulmán. Sí se proyecta una imagen de rechazo hasta el punto de leerse definiciones del hiyab como "castrador velo" ${ }^{28}$ y del islam como "ideología de imposición" ${ }^{29}$. De hecho, la mayoría de los registros de sujeto ven al musulmán como un extraño (enfoque excluyente) perteneciente a una comunidad de iguales indiferenciados (homogéneo). En consecuencia, sí existe un discurso racista sobre, a propósito de ese otro islamizado. Ahora bien, si por una parte los enfoques del marco integrador suponen al menos una cuarta parte de la cobertura, el no-problemático iguala al problemático. En el caso de las voces y fuentes, incluso lo supera.

En síntesis y a la luz de los datos, la cobertura española es más homogeneizadora que excluyente, si bien tiene ambas derivas islamófobas. En cambio, resulta más equilibrada en su proyección de lo islámico como problema, y de hecho tiende a no proyectarlo como tal. La pluralidad informativa se traduce, en todo caso, en pluralidad de enfoques. Queda, pues, confirmada la $h_{2}$ y matizada la $h_{1}$. Tanto más es así dado que la diversidad de enfoques se ve acompañada de pluralidad de voces: institucionales y no-institucionales y tanto musulmanas como no-musulmanas. Al respecto, cabe concluir, a) que no hay silenciamiento o exclusión ni de las voces musulmanas ni de las extrainstitucionales, y b), que predominan las institucionales y las no-musulmanas, ambas con enfoques islamófobos, pero también aquí con excepción del problemático.

Se confirman asimismo las hipótesis $h_{3}$ y $h_{4}$ : LV aparece menos integrador que EP, pero más que $A B C$, de donde cabe inferir que, importando la ideología, no resulta relevante la territorialidad, en este caso definida tanto por la identidad diferenciada del territorio de referencia como por el volumen de población procedente de países mayoritariamente musulmanes. De EP cabe añadir que es además el medio que menos islamiza contenidos, tanto por el número de piezas publicadas como por el total de palabras de su cobertura, así como por el volumen de entradas de opinión, aspecto éste en el que de nuevo aparece LV entre el diario de izquierda y el de derecha. Respecto del total de piezas publicadas, es reseñable que lo publicado por cada uno de ellos se reduzca a menos de un tercio de los días del año. A falta de elementos comparativos con otros sistemas mediáticos, permite intuir voluntad por no islamizar los contenidos de la agenda pública. Abonaría la hipótesis el escaso porcentaje de noticias específicamente referidas al caso español. Queda planteada, en todo caso, como sugerencia para futuras investigaciones.

El análisis de los temas mediatizados corrobora las conclusiones alcanzadas hasta aquí y permite validar asimismo la $h_{5}$. Particularmente esclarecedora ha resultado la atención a las piezas publicadas en el contexto de los atentados de agosto: en un momento susceptible de experimentar reacciones racistas, islamófobas, tanto EP como LV optaron por reducir la presencia del enfoque islamófobo y por incrementar la del integrador. $A B C$ optó por un discurso algo más islamófobo que el que viniera sosteniendo (mayor en menos de cinco puntos porcentuales para

\footnotetext{
${ }^{28}$ Abc, 22-5-17, p.76.

${ }^{29}$ La Vanguardia, 18-3-17, p.23.
} 
cada enfoque islamófobo), pero redujo su cobertura a menos de la mitad de piezas que los otros dos diarios; así, devino más islamófobo al tiempo que, neutralizando potencialmente su impacto social, islamizó en menor medida.

Con las diferencias apuntadas entre medios y desde la diversidad de enfoques asimismo constatada, la prensa española proyecta una imagen más bien homogénea del islam y tiende a construirlo como un otro diferenciado o ajeno, extraño, implícitamente excluido del nosotros de referencia. No estaría contribuyendo a la inclusión del musulmán como parte de una realidad multicultural de la que lo islámico, asimismo plural, también forma parte. Pero tampoco puede decirse del discurso mediático que esté alimentando miedos, tensiones ni hostilidades hacia los musulmanes. Más bien aparecen estos y su religión como una cuestión que se evita, tanto por los temas y los sujetos que no se islamizan (la inmigración y la crisis humanitaria de los refugiados o los reformadores y las feministas, entre otros) como por la relevante presencia del enfoque neutro en los contenidos islamizados. Esta suerte de silencio podría ayudar a entender la ausencia de rechazo por parte de la opinión pública española, el habitus bourdieano que se estaría contribuyendo a conformar, pero podría estar implicando también una ausencia de conocimiento del igual distinto con el que cada vez se convive más en la orilla norte del Mediterráneo.

\section{Referencias $^{30}$}

ABELLA, Carlos (2005): Los discursos mediáticos acerca de la inmigración y el multiculturalismo en España: análisis de los editoriales de ABC, El Mundo y El País, 1994-2002. Tesis Doctoral, Universidad de la Coruña.

ADLBI, Sirin (2017): La cárcel del feminismo, Madrid, Akal.

AHMED, Saifuddin y MATTHES, Jörg (2016): 'Media representation of Muslims and Islam from 2000 to 2015', The International Communication Gazette, vol. 79, no 3, pp. 219-244. DOI: $10.1177 / 1748048516656305$.

ALBA, Santiago (2015): Islamofobia. Nosotros, los otros, el miedo, Barcelona, Icaria.

ALBIZU, Xabier (2016): 'Interpretando los escraches: La prensa española en el proceso de opinión pública', Communication\&Society, vol. 29, no 1, pp. 83-100.

ALCÁNTARA-PLA, Manuel y Ruiz-Sánchez, Ana (2017): 'The framing of Muslims in the Spanish Internet', Lodz Papers in Pragmatics, vol. 13, no 2, pp. 261-283. DOI: 10.1515/lpp-2017-0013.

ALONSO, Sonia y ROVIRA, Cristóbal (2015). 'Spain: No country for the populist radical right?', South European Society and Politics, no 20, pp. 21-45.

AMELI, Saied y MERALI, Arzu (2015): Environment of hate: The new normal for Muslims in the UK, Wembley, Islamic Human Rights Commission (IHRC).

ANDERSON, Leticia (2015): 'Countering Islamophobic media representations', Global Media and Communication, vol. 11, no 3, pp. 255-270.

BAKER, Paul; GABRIELATOS, Costas, y McENERY, Tony (2013a): 'Sketching Muslims: A corpus driven analysis of representations around the word 'Muslim' in the British press 1998-2009', Applied Linguistics, vol. 34, no 3, pp. 255-278. DOI: 10.1093/applin/ams048.

BAKER, Paul; GABRIELATOS, Costas, y McENERY, Tony (2013b): Discourse analysis and media attitudes: The representation of Islam in the British Press, Cambridge, Cambridge University Press. BAUMAN, Zygmunt (2016): Strangers at our door, Cambridge, Polity Press.

BAYRAKLI, Enes y HAFEZ, Farid (eds.) (2016): 'Introduction', en idem (eds.): European Islamophobia report 2015, Estambul, Foundation for Political, Economic and Social Research, pp. 1-4.

\footnotetext{
${ }^{30}$ Consulta de las referencias de internet: 5 de diciembre, 2018.
} 
BERBERS, Anna; JORIS, Willem; BOESMAN, Jan; D'HAENENS, Leen; KOEMAN, Joyce y VAN GORP, Baldwin (2016): 'The news framing of the 'Syria fighters' in Flanders and the Netherlands: Victims or terrorists?', Ethnicities, vol. 16, no 6, pp. 798-818. DOl: 10.1177/1468796815603753.bourd.

BLEICH, Erik (2011): 'What is Islamophobia and how much is there? Theorizing and measuring an emerging comparative concept', American Behavioral Scientist, vol. 55, no 12, pp. 1581-1600. BOURDIEU, Pierre (2007): Razones prácticas. Sobre la teoría de la acción, Barcelona, Anagrama. BOWE, Brian J. y MAKKI, Taj W. (2016): 'Muslim neighbors or an Islamic threat? A constructionist analysis of newspaper coverage of mosque controversies', Media, Culture \& Society, vol. 38, no 4, pp. 540-558.

BOWE, Brian; FAHMY, Shahira y MATTHES, Jorg (2015): 'U.S. newspapers provide nuanced picture of Islam', Newspaper Research Journal, vol. 36, no 1, pp. 42-57. DOI: 10.1177/0739532915580312. BROWN, Malcolm D. (2006): "Comparative analysis of mainstream discourses, media narratives and representations of Islam in Britain and France prior to 9/11", Journal of Muslim Minority Affairs, vol. 26, no 3, pp. 297-312. DOI: 10.1080=13602000601141216.

BULKOW, Kristin; URBAN, Juliane y SCHWEIGER, Wolfgang (2013): "The duality of agenda-setting: The role of information processing", International Journal of Public Opinion Research, vol. 25, no 1, pp. 43-63.

BUTLER-SLOSS, Elizabeth y KESSLER, Ed (2015): Living with difference: community, diversity and the common good. Report of the commission on religion and belief in British public life, Cambridge, The Woolf Institute.

CEBOLLA, Héctor y GONZÁLEZ FERRER, Amparo (2008): La inmigración en España (2000-2007), Madrid, CEPC.

CHOULIARAKI, Lilie (2013): 'Re-mediation, inter-mediation, trans-mediation', Journalism Studies, vol. 14, no 2, pp. 267-283. DOI: 10.1080/1461670X.2012.718559.

CHOULIARAKI, Lilie y ZABOROWSKI, Rafal (2017): 'Voice and community in the 2015 refugee crisis: A content analysis of news coverage in eight European countries', International Communication Gazette, vol. 79, no 6-7, pp. 613-635. DOI: 10.1177/1748048517727173.

CORM, Georges (2004): La fractura imaginaria. Las falsas raíces del enfrentamiento entre Oriente $y$ Occidente, Barcelona, Tusquets

CORRAL, Alfonso (2014): '¿lslamofobia en la prensa digital? Análisis de los comentarios en La inocencia de los musulmanes', en Fernando Sabés y José Verón (coords.): Universidad, investigación y periodismo digital, Zaragoza: Asociación de Periodistas de Aragón, pp. 5-18.

CREUTZ-KÄMPPI, Karin (2008): 'The othering of Islam in a European context: polarizing discourses in Swedish-language dailies in Finland', Nordicom Review, vol. 29, n 2, pp. 295-308.

D'HAENENS Leen y BINK, Susan (2007): 'Islam in the Dutch press: With special attention to the Algemeen Dagblad', Media, Culture and Society, vol. 29, no 1, pp. 135-149. DOI: 10.1177/0163443706072002.

DE BELLAIGUE, Christopher (2018): 'The new Europeans', The New York Review of Books, 7 de junio.

DE VREESE, Claes H.; BOOMGAARDEN, Hajo G. y SEMETKO, Holli A. (2011): '(In)direct framing effects: the effects of news media framing on public support for Turkish membership in the European Union', Communication Research, vol. 38, no 2, pp. 179-205.

DESRUES, Thierry y PÉREZ-YRUELA, Manuel (2008): 'Percepciones y actitudes hacia el islam y los musulmanes en España: avance de resultados', informe del OBERAXE.

DURÁN, Rafael (2014): 'Cifras de una sociedad transformada: Los españoles ante la inmigración y los modos de gestión de la diversidad', en Patricia Laurenzo y Rafael Durán (coords.): Diversidad cultural, género y Derecho, Valencia, Tirant lo Blanch pp. 93-148. 
DURÁN, Rafael (2015): 'El problema de los otros. Encuadre de inmigrantes y/o desplazados en la Lampedusa de la Primavera Árabe', Revista de Estudios Políticos, no 169, pp. 299-331. DOI: 10.18042/cepc/rep.169.10.

ELAHI, Farah y KHAN, Omar (eds.) (2017): Islamophobia. Still a challenge for us all, Londres, Runnymede.

ENTMAN, Robert M. (1993): 'Framing: Toward clarification of a fractured paradigm'. Journal of Communication, vol. 43, no 4, pp. 51-58. DOI: 10.1111/i.1460-2466.1993.tb01304.x.

ENTMAN, Robert M. (2007): 'Framing bias: Media in the distribution of power'. Journal of Communication, no 57, pp. 163-173. DOI: 10.1111/j.1460-2466.2006.00336.x

FELICETTI, Andrea y GATTINARA, Pietro (2018): 'Toward an assessment of marginality in democratic systems: The Charlie Hebdo debate in the United Kingdom', The British Journal of Politics and International Relations, vol. 20, no 2, pp. 497-517. DOI: 10.1177/1369148118758237. FERNÁNDEZ-SUÁREZ, Belén (2016): 'La imagen de las mujeres inmigrantes en España: la construcción de la alteridad victimizada en los discursos políticos y mediáticos a través del debate sobre el uso de la burka', Revista Internacional de Comunicación y Desarrollo, vol. 1, no 3, pp. 107123. DOI: 10.15304/ricd.1.3.2532.

GILSON, Chris y PHOTIADOU, Artemis: 'Interview with Eric Kaufmann: cultural values and the rise of right-wing populism in the West', British Politics and Policy, 2 de febrero, 2017, disponible en http://blogs.Ise.ac.uk/politicsandpolicy/interview-with-eric-kaufmann.

GIVENS, Terri y LUEDTKE, Adam (2005): 'European immigration policies in comparative perspective: Issue salience, partisanship and immigrant rights', Comparative European Politics, vol. 3, no 1, pp. 1-22. DOI: 10.1057/palgrave.cep.6110051.

GÓMEZ, Luz: 'Dios es lo más: jóvenes musulmanes e islamofobia', Estudios de Política Exterior, no 50, 2016, disponible en http://www.politicaexterior.com/articulos/afkar-ideas/dios-es-lo-masjovenes-musulmanes-e-islamofobia.

GÓMEZ, Luz: Diccionario de islam e islamismo, Madrid, Trotta.

GREENBERG, David y MIAZHEVICH, Galina (2012): 'Assimilationism vs. multiculturalism: U.S. identity and media representations of British Muslims over a 12-year span', Communication, Culture \& Critique, № 5, pp. 75-98. DOI: 10.1111/i.1753-9137.2011.01117.x.

HADIZ, Vedi R. y CHRYSSOGELOS, Angelos (2017): “Populism in world politics: A comparative crossregional perspective", International Political Science Review, vol. 38, no 4, pp. 399-411. DOI: 10.1177/0192512117693908.

HAFEZ, Farid (2010): Islamophober populismus: Moschee- und minarettbauverbote Österreichischer parliamentsparteien, Wiesbaden, VS.

HAFEZ, Farid (2017): 'Debating the 2015 Islam law in Austrian Parliament: Between legal recognition and Islamophobic populism', Discourse\&Society, vol. 28, no 4, pp. 392-412. DOI: 10.1177/0957926517703223.

HAJJAT, Abdellali y MOHAMMED, Marwan (2016): Islamophobie. Comment les élites françaises fabriquent le "problème musulman», París, La Découverte.

HOFFMAN, Bruce y REINARES, Fernando (eds.) (2014): The evolution of the global terrorist threat. From 9/11 to Osama Bin Laden's death, Nueva York, Columbia University Press.

IBRAHIM, Dina (2010): 'The framing of Islam on network news following the September $11^{\text {th }}$ attacks'. International Communication Gazette, vol. 72, no 1, pp. 111-125.

IMHOFF, Ronald, y RECKER, Julia (2012): 'Differentiating islamophobia: Introducing a new scale to measure islamoprejudice and secular Islam critique', Political Psychology, vol. 33, no 6, pp. 811824. DOI: 10.1111/j.1467- 9221.2012.00911.x. 
IYENGAR, Shanto (1994): Is anyone responsible? How television frames political issues, Chicago, University of Chicago Press.

KAUFMANN, Eric y GOODWIN, Matthew (2018): 'The diversity wave: A meta-analysis of the nativeborn white response to ethnic diversity', Social Science Research, no 76, pp. 120-131. DOI: 10.1016/j.ssresearch.2018.07.008.

KAYA, Ayhan (2015): 'Islamophobism as an ideology in the West: Scapegoating Muslim-origin migrants', en Anna Amelina, Kenneth Horvath y Bruno Meeus (eds.): International handbook of migration and social transformation in Europe, Wiesbaden, Springer.

KAYA, Ayhan (2017): 'Populismo e inmigración en la Unión Europea', en Joaquín Arango et al. (eds.): Anuario CIDOB de la Inmigración 2017, Barcelona, CIDOB, pp. 52-79.

KESKINEN, Suvi (2014): 'Re-constructing the peaceful nation: negotiating meanings of whiteness, immigration and Islam after a shopping mall shooting', Social Identities, vol. 20, no 6, pp. 471-485. DOI: 10.1080/13504630.2015.1004828.

KHADER, Bichara: 'Reflexiones sobre la islamofobia ordinaria', Estudios de Política Exterior, no 50, 2016, disponible en http://www.politicaexterior.com/articulos/afkar-ideas/reflexiones-sobre-laislamofobia-ordinaria.

LUHMANN, Niklas (2000): La realidad de los medios de masas, Madrid, Anthropos.

MALIK, Kenan (2015): 'Assimilationism vs multiculturalism', Pandemonium, 12 de enero de 2015, disponible en https://kenanmalik.com/2015/01/12/assimilationism-vs-multiculturalism.

MARTíN, Gema (2012): 'La islamofobia inconsciente', en Gema Martín y Ramón Grosfoguel (eds.): La islamofobia a debate, Madrid, Casa Árabe, pp. 35-46.

MARTíN, Gema; HERNÁNDEZ, Julia y LÓPEZ, Mã Ángeles (1997): La imagen de la mujer musulmana en los medios de comunicación españoles, Madrid, Instituto Universitario de Estudios de la Mujer. MASSOUMI, Narzanin, MILLS, Tom y MILLER, David (eds.) (2017): What is Islamophobia? Racism, social movements and the State, Londres, Pluto Press.

McCOMBS, Maxwell E. y SHAW, Donald (1972): 'The agenda-setting function of mass media', Public Opinion Quarterly, vol. 36, no 2, pp. 176-187.

McELWEE, Sean y McDANIEL, Jason: 'Do racists like Fox News, or does Fox make people racist?', $F A I R, 22$ de diciembre de 2015, disponible en https://fair.org/home/do-racists-like-fox-news-ordoes-fox-make-people-racist.

MIJARES, Laura y LEMS, Johanna M. (2018): 'Luchando contra la subalternidad: las reivindicaciones de la población musulmana en Madrid', Revista de Estudios Internacionales Mediterráneos, no 24, pp. 109-128. DOI: 10.15366/reim2018.24.007.

MORIN, Aysel (2016): 'Framing terror: The strategies newspapers use to frame an act as terror or crime', Journalism \& Mass Communication Quarterly, vol. 93, no 4, pp. 986-1.005. DOI: $10.1177 / 1077699016660720$.

NACOS, Brigitte L. y TORRES-REYNA, Óscar (2007): Fueling our fears: Stereotyping, media coverage, and public opinion of Muslim Americans, Nueva York, Rowman \& Littlefield Publishers.

NAVARRO, Laura (2012): 'Islamofobia y sexismo. Las mujeres musulmanas en los medios de comunicación occidentales', en Gema Martín y Ramón Grosfoguel (eds.): La islamofobia a debate, Madrid, Biblioteca de Casa Árabe, pp. 141-166.

NEUMANN, Peter (2016): Radicalized: new jihadists and the threat to the West, Londres, Tauris.

PEW RESEARCH CENTER: "Eastern and Western Europeans differ on importance of religion, views of minorities, and key social issues", 29 de octubre de 2018, disponible en http://www.pewforum.org/2018/10/29/eastern-and-western-europeans-differ-on-importance-ofreligion-views-of-minorities-and-key-social-issues.

PIQUER, Sara (2015): 'La islamofobia en la prensa escrita española: aproximación al discurso periodístico de El País y La Razón', Dirasat Hispánicas, no 2, pp. 137-156. 
REVENGA, Miguel y EL MOUDEN, Anass (2010): 'The politics of integration in Spain', comunicación, World Congress for Middle Eastern Studies, Barcelona, 19-24 de julio.

RICHARDSON, Robin (ed.) (1997): Islamophobia: A challenge for us all. Report of the Runnymede Trust Commission on British Muslims and Islamophobia, Londres, Runnymede Trust.

RIZVI, Ali (2016): The atheist Muslim. A journey from religion to reason, Nueva York, St. Martin's Press.

RODRÍGUEZ-PÉREZ, Carlos (2017): 'News framing and media legitimacy: an exploratory study of the media coverage of the refugee crisis in the European Union', Communication\&Society, vol. 30, no 3, pp. 169-184. DOI: 10.15581/003.30.3.169-184.

ROGGEBAND, Conny y VLIEGENTHART, Rens (2007): 'Divergent framing: The public debate on migration in the Dutch parliament and media, 1995-2004', West European Politics, vol. 30, no 3, pp. 524-548. DOI: 10.1080/01402380701276352.

SAEED, Amir (2007): 'Media, racism and Islamophobia: The representation of Islam and Muslims in the media', Sociology Compass, vol. 1, no 2, pp. 443-462.

SAID, Edward (1990): Orientalismo, Madrid, Libertarias.

SAID, Edward (2005): Cubriendo el islam: Cómo los medios de comunicación y los expertos determinan nuestra visión del resto del mundo, Barcelona, Debate.

SALEEM, Muniba; PROT, Sara; ANDERSON, Craig y LEMIEUX, Anthony (2015): 'Exposure to Muslims in media and support for public policies harming Muslims', Communication Research, vol. 44, no 6, pp. 841-869. DOI: 10.1177/0093650215619214.

SCALVINI, Marco (2016): 'A crisis of religious diversity: Debating integration in post-immigration Europe'. Discourse \& Communication, vol. 10, no 6, pp. 614-634. https://doi.org/10.1177/1750481316674779.

SCHEUFELE, Dietram e IYENGAR, Shanto (2011): 'The state of framing research: A call for new directions', Political Communication Lab Research Papers (Stanford University).

SCHEUFELE, Dietram y TEWKSBURY, David (2007): 'Framing, agenda-setting and priming: The evolution of three media effects models', Journal of Communication, vol. 57, no 1, pp. 9-20. DOl: 10.1111/i.0021-9916.2007.00326.x.

SLAUGHTER, Anne-Marie: 'Nationalists and globalists', Project Syndicate, 23 de marzo de 2017, disponible en https://www.project-syndicate.org/commentary/nationalists-and-globalists-trumpwilders-by-anne-marie-slaughter-2017-03.

SLONE, Michelle (2000): "Responses to media coverage of terrorism", Journal of Conflict Resolution, vol. 44, no 4, pp. 508-522.

UCIDE (2018): Estudio demográfico de la población musulmana. Explotación estadística del censo de ciudadanos musulmanes en España referido a fecha 31/12/2017, Madrid, Observatorio Andalusí, disponible en http://www.observatorioislamofobia.org/2018/02/19/estudio-demografico-lapoblacion-musulmana-espana-31-12-17/.

UITERMARK, Justus y GIELEN, Amy-Jane (2010): 'Islam in the spotlight: the mediatisation of politics in an Amsterdam neighbourhood', Urban Studies, vol. 47, no 6, pp. 1.325-1.342. DOI: 10.1177/0042098010362807.

VAN DIJK, Teun (1993): 'Principles of critical discourse analysis', Discourse\&Society, vol. 4, no 2, pp. 249-283.

VAN DIJK, Teun (1997): Racismo y análisis crítico de los medios, Barcelona, Paidós.

ZURBANO, Belén; ORTEGA, Ana Mạ y TARÍN, Adrián (2017): 'Violencias contra las mujeres en contextos islámicos. Representación y discurso de la prensa de referencia de España', Estudios sobre el Mensaje Periodístico, vol. 23, № 2, pp. 1.023-1.043. DOI: 10.5209/ESMP.58030. 